\title{
Cholesterol sensing by CD81 is important for hepatitis C virus entry
}

Received for publication, June 10, 2020, and in revised form, August 11, 2020 Published, Papers in Press, September 8, 2020, DOI 10.1074/jbc.RA120.014761

Machaela Palor ${ }^{1, \neq}$, Lenka Stejskal ${ }^{1,2, \neq}$, Piya Mandal ${ }^{1}$, Annasara Lenman ${ }^{3,4}$, María Pía Alberione $^{4}$, Jared Kirui ${ }^{4}{ }^{\circ}$, Rebecca Moeller ${ }^{4}$, Stefan Ebner ${ }^{5}$, Felix Meissner ${ }^{5,6} \oplus$, Gisa Gerold ${ }^{3,4,7} \oplus$, Adrian J. Shepherd ${ }^{2}$, and Joe Grove ${ }^{1, *} \mathbb{E}$ From the ${ }^{1}$ Institute of Immunity and Transplantation, Division of Infection and Immunity, University College, London, United Kingdom, the Institute of Structural and Molecular Biology, Birkbeck College, London, United Kingdom, the ${ }^{3}$ Department of Clinical Microbiology, Virology \& Wallenberg Centre for Molecular Medicine, Umeå University, Umeå, Sweden, the ${ }^{4}$ Institute for Experimental Virology, TWINCORE, Centre for Experimental and Clinical Infection Research, a joint venture between the Medical School Hannover and the Helmholtz Centre for Infection Research, Hannover, Germany, the ${ }^{5}$ Experimental Systems Immunology, Max Planck Institute of Biochemistry, Martinsried, Germany, the ${ }^{6}$ Institute of Innate Immunity, Department of Systems Immunology and Proteomics, Medical Faculty, University of Bonn, Bonn, Germany, and the Department of Physiological Chemistry, University of Veterinary Medicine Hannover, Hannover, Germany

Edited by Craig E. Cameron

CD81 plays a central role in a variety of physiological and pathological processes. Recent structural analysis of CD81 indicates that it contains an intramembrane cholesterol-binding pocket and that interaction with cholesterol may regulate a conformational switch in the large extracellular domain of CD81. Therefore, CD81 possesses a potential cholesterol-sensing mechanism; however, its relevance for protein function is thus far unknown. In this study we investigate CD81 cholesterol sensing in the context of its activity as a receptor for hepatitis $\mathrm{C}$ virus (HCV). Structure-led mutagenesis of the cholesterolbinding pocket reduced CD81-cholesterol association but had disparate effects on $\mathrm{HCV}$ entry, both reducing and enhancing CD81 receptor activity. We reasoned that this could be explained by alterations in the consequences of cholesterol binding. To investigate this further we performed molecular dynamic simulations of CD81 with and without cholesterol; this identified a potential allosteric mechanism by which cholesterol binding regulates the conformation of CD81. To test this, we designed further mutations to force CD81 into either the open (cholesterol-unbound) or closed (cholesterol-bound) conformation. The open mutant of CD81 exhibited reduced HCV receptor activity, whereas the closed mutant enhanced activity. These data are consistent with cholesterol sensing switching CD81 between a receptor active and inactive state. CD81 interactome analysis also suggests that conformational switching may modulate the assembly of CD81-partner protein networks. This work furthers our understanding of the molecular mechanism of CD81 cholesterol sensing, how this relates to HCV entry, and CD81's function as molecular scaffold; these insights are relevant to CD81's varied roles in both health and disease.

Binding of the $\mathrm{E} 2$ glycoprotein of hepatitis $\mathrm{C}$ virus (HCV) to the large extracellular loop of CD81 is a defining event in the

This article contains supporting information.

$\because$ Author's Choice-Final version open access under the terms of the Creative Commons CC-BY license.

${ }^{\ddagger}$ These authors contributed equally to this work.

*For correspondence: Joe Grove, j.grove@ucl.ac.uk. entry of HCV (1) and is targeted by multiple broadly neutralizing antibodies, thus placing this molecular interaction at the forefront of current HCV vaccine development (2, 3). Although the importance of CD81 in HCV entry is well-established, the precise details of E2-CD81 interaction have yet to be defined, and the molecular determinants of CD81 receptor activity are only partially understood (4).

CD81 is a prototypical member of the tetraspanin superfamily. Tetraspanins are small integral membrane proteins defined by their four transmembrane domains separated by intra-/ extracellular loops. Highly conserved cysteine residues stabilize tetraspanin tertiary structure through disulfide bridges and provide sites for post-translational palmitoylation, which influences tetraspanin membrane segregation $(5,6)$.

Largely without cognate ligands, tetraspanins participate indirectly in a wide variety of cell-biological processes through their interactions with partner proteins, which they organize into functional complexes $(7,8)$. For example, CD81 facilitates the assembly of the B-cell receptor complex and is therefore essential for normal antibody responses. CD81 performs this role via partnership with CD19; first by chaperoning CD19 through the secretory pathway and then by dictating its cellsurface distribution, permitting proper assembly of the B-cell receptor complex upon activation (9-12). Through other molecular partnerships, CD81 has been implicated in additional physiological processes such as T-cell receptor signaling, cell migration, growth factor signaling, sperm-egg fusion, and most recently, biological aging, potentially through its interaction with TMEM2 (13-19).

Aside from these physiological functions, CD81 is also commandeered by diverse infectious pathogens. It participates in the cell-surface assembly of both HIV and influenza A virus, a function that may be linked to the apparent affinity of CD81 for membrane structures with high curvature (20-23). CD81 also negatively regulates SAMHD1 function, resulting in increased intracellular pools of dNTPs, which in turn favors HIV reverse transcription (24). Finally, CD81 is critical for the entry of HCV and Plasmodium sporozoites into human hepatocytes $(1,25)$. In summary, CD81 performs molecular scaffolding function in 
a variety of pathways; a greater understanding of its molecular characteristics will provide novel insights into both physiological and pathological processes.

The recent crystal structure of CD81, the first of any tetraspanin, has provided a novel perspective on its molecular biology (26). CD81's four helical transmembrane domains are arranged in a loose bundle forming an inverted conical shape. Curiously, the transmembrane domains enclose a central intramembrane cavity filled by a single molecule of cholesterol, which is coordinated by hydrogen bonding to the side chains of inward-facing amino acids. Although this observation may have arisen because of the presence of cholesterol in the crystallization buffer, Zimmerman et al. (26) use biochemical experiments to demonstrate physical association of CD81 with cholesterol. Moreover, this finding is consistent with other reports linking cholesterol to tetraspanin biology $(27,28)$.

Whereas the minor extracellular domain (EC1) was not resolved in the crystal structure (Protein Data Bank code 5TCX (26)), CD81's major extracellular domain (EC2) was found to be roughly parallel to the plane of the plasma membrane, analogous to a lid sitting on top of the bundle of transmembrane domains (Fig. $1 A$ and Fig. S2A). Overall, CD81 adopts a compact structure that is likely to project only a few nanometers from the cell surface. However, using molecular dynamic simulations, Zimmerman et al. (26) demonstrated that the EC2 of CD81 has a propensity to flip up into an extended open conformation (Fig. S2A). Furthermore, removal of cholesterol from the intramembrane cavity during the simulations increased the frequency of conformational switching, suggesting an allosteric link between cholesterol binding and CD81 conformation. These observations indicate that CD81 may have an as-yet unappreciated function as a cholesterol sensor; this feature is likely to be important for its role in scaffolding events occurring at cellular membranes.

Although the precise molecular interaction of HCV E2 with the EC2 of CD81 has yet to be structurally defined, the relevant protein domains have been identified (29-34). The CD81-binding site of HCV E2 comprises discontinuous protein regions, brought together in the 3D structure of the glycoprotein; these regions interact with helices D and E of CD81's EC2, which are presented at the apex of CD81's closed compact structure. Antibodies that prevent this interaction block HCV entry, and cells without CD81 are completely resistant to infection (3544). The ability of CD81 to recruit molecular partners is also likely to be important for HCV infection; indeed, other HCV entry factors constitutively associate with $\operatorname{CD} 81(8,45)$. Significantly, HCV entry also seems to be closely linked to cell-surface cholesterol transport: three cholesterol-transporting proteins (SR-B1, LDLR, and NPC1L1) have been implicated in the process (46). Notably, the cholesterol transporter scavenger receptor B-1 (SR-B1) naturally associates with CD81 and also modulates the CD81-dependent invasion of Plasmodium sporozoites into hepatocytes $(8,47,48)$.

The biology of both CD81 and HCV converge on plasma membrane cholesterol; therefore, we set out to investigate how CD81's interaction with cholesterol impacts HCV infection. First, we mutated residues within the cholesterol-binding pocket of CD81. Although all of the tested mutations reduced
CD81-cholesterol association, they had varying effects on $\mathrm{HCV}$, both decreasing and increasing virus entry. This suggests the cholesterol-binding pocket of CD81 is important for HCV infection, but viral entry may not be directly dependent on cholesterol association. We performed multiple independent molecular dynamics (MD) simulations of CD81 behavior with and without cholesterol. In support of the report by Zimmerman et al. (26), we demonstrate a cholesterol-dependent conformational switch of CD81; this is consistent with the notion of cholesterol sensing by CD81. These experiments identified a potential hinging between CD81's EC2 and transmembrane domains. We designed mutations to alter this motion and, therefore, disrupt CD81's cholesterol-sensing mechanism. Mutations that are predicted to confer the open conformation (i.e. the cholesterol-unbound state) reduced HCV entry, whereas mutations that confer the closed conformation (i.e. cholesterol-bound state) enhanced HCV entry. Further characterization of these mutants demonstrate that they exhibit normal cell-surface expression and distribution and retain the ability to chaperone CD19 to the cell surface. However, the open mutant of CD81 exhibits reduced interaction with $\mathrm{HCV}$ E2. We also use diverse cell culture-proficient $\mathrm{HCV}$ to demonstrate that cholesterolbinding and open conformation mutants of CD81 do not support authentic viral replication. This study provides further insight into the molecular mechanism of cholesterol sensing by CD81 and demonstrates that this activity is important for $\mathrm{HCV}$ infection.

\section{Results}

\section{Mutations in the cholesterol-binding pocket of CD81 modulate HCV entry}

The crystal structure of CD81 (Protein Data Bank code 5TCX (26)) reveals an intramembrane cavity bounded by the four transmembrane domains; this contains a single molecule of cholesterol, which is coordinated by hydrogen bonding to the side chains of two residues, $\mathrm{Asn}^{18}$ and Glu ${ }^{219}$ (Fig. 1A). We designed a series of mutants to disrupt this interaction: E219A and E219Q, which were previously demonstrated to reduce CD81-cholesterol association (26), and an N18A/E219A double mutation, which should remove all possibility of hydrogen bonding to cholesterol. Many of the inward-facing residues of CD81's intramembrane cavity have small side chains (e.g. alanine, valine, glycine), this creates a binding pocket to accommodate cholesterol. Therefore, we also mutated four inward-facing residues to tryptophan (V68W/M72W/A108W/ V212W), the side chain of which includes a bulky indole group. Structural modeling predicts that these tryptophan residues will fill the cholesterol-binding pocket while maintaining the hydrophobic nature of the transmembrane domains (Fig. 1B). We introduced each of the cholesterol-binding-pocket mutants into Huh-7 CD81 KO cells by lentiviral transduction and confirmed that their cell-surface expression was equivalent to WT CD81 (Fig. 1C).

Zimmerman et al. (26) previously demonstrated CD81-cholesterol association by the addition of exogenous cholesterol to purified CD81; we corroborated this by examining the interaction of CD81 with endogenous plasma membrane-resident 
A.

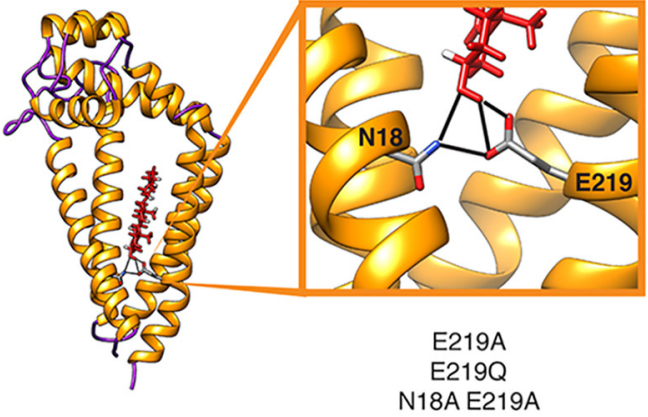

C.

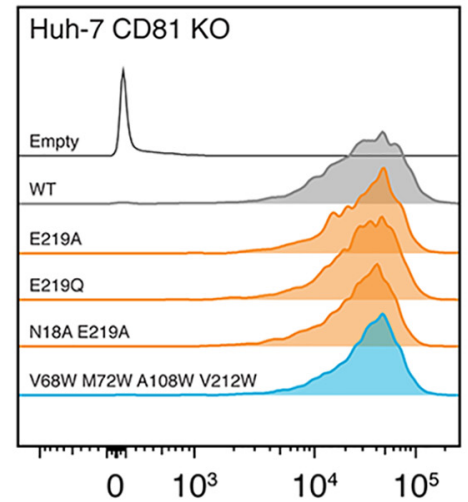

B.
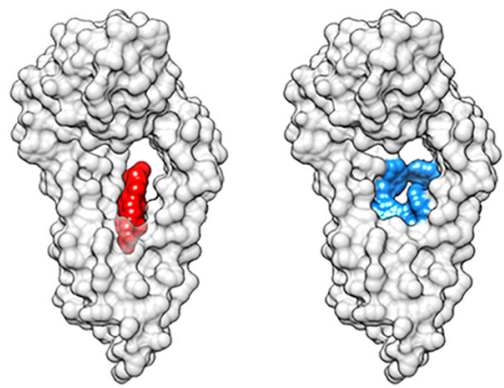

V68W M72W A108W V212W
D.

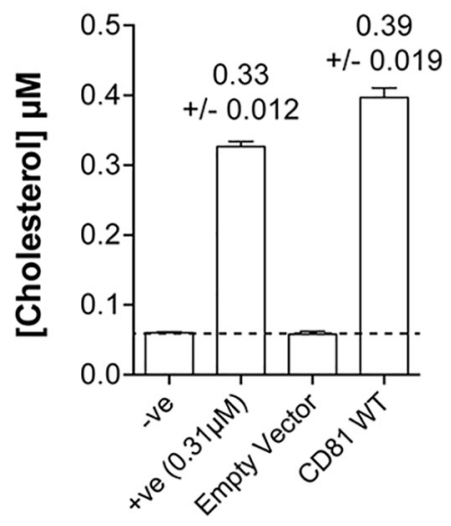

E.
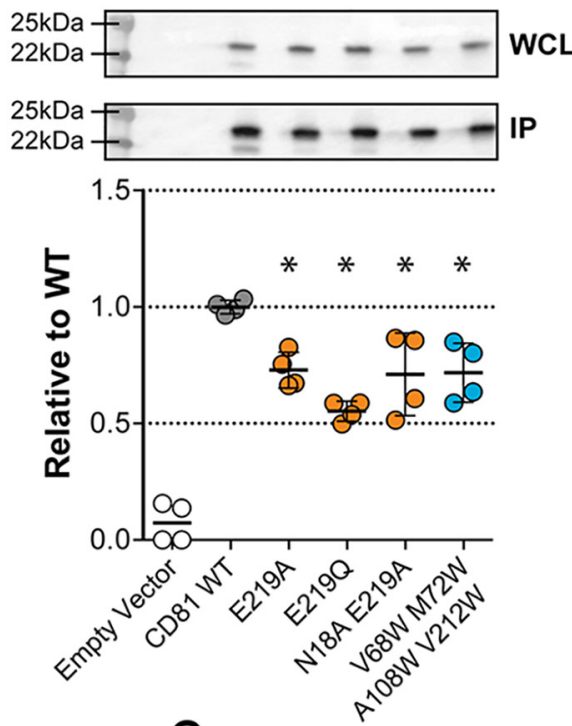

F.
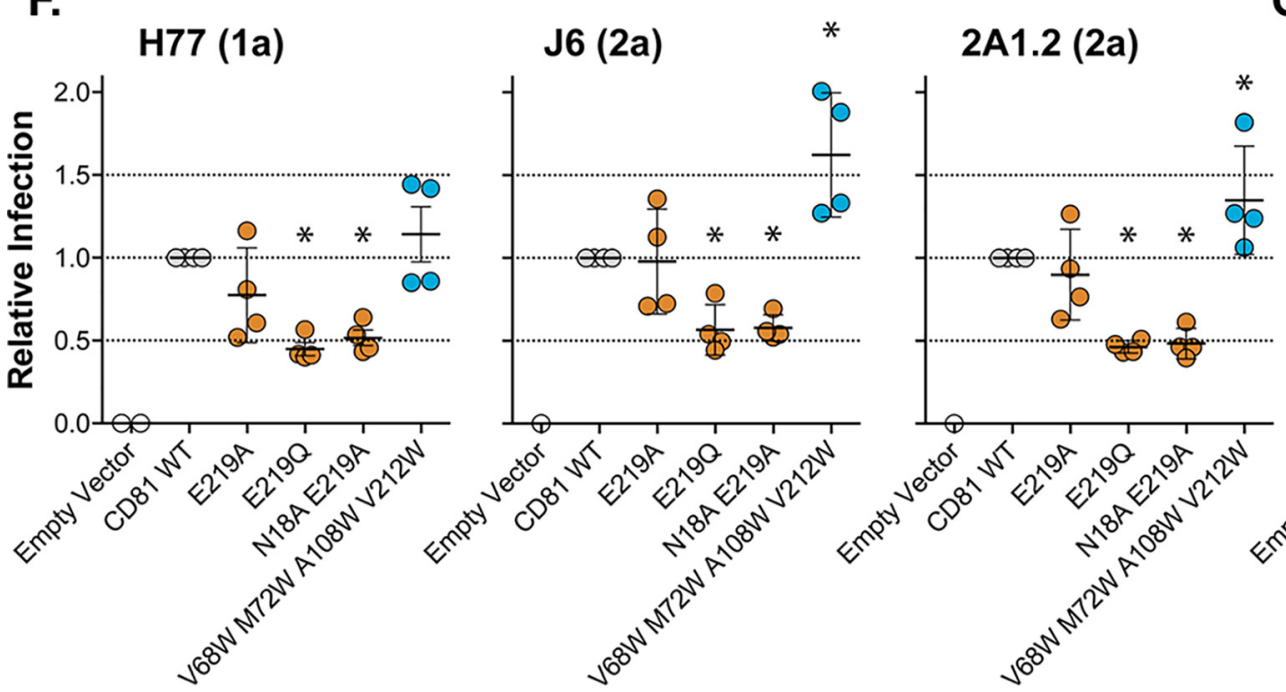

G.

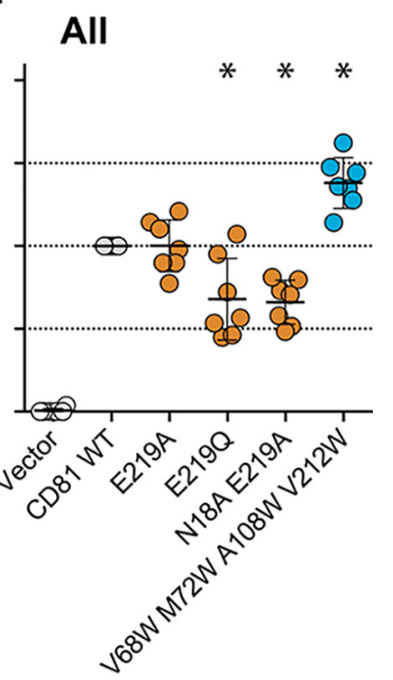

Figure 1. Mutations in the cholesterol-binding pocket of CD81 modulate HCV entry. $A$, cholesterol (red) is coordinated in the intramembrane cavity of CD81 by hydrogen bonds with inward-facing residues Asn ${ }^{18}$ and $\mathrm{Glu}^{219}$. We made various mutations at these sites to disrupt this interaction. $B$, the cholesterol molecule sits in the center of an intramembrane-binding pocket. In the V68W/M72W/A108W/V212W mutant, this space is occupied by tryptophan residues (blue). Molecular model images were created using Protein Data Bank code 5TCX (26). C, the cell-surface expression levels of each mutant CD81 was assessed by flow cytometry. D, Huh-7 CD81 KO cells were transduced with lentivector encoding WT CD81 or empty vector control. The cells were surface-labeled with anti-CD81 mAb and lysed in Brij-98 detergent buffer. CD81-mAb complexes were pulled down with protein $\mathrm{G}$ beads, and associated free cholesterol was measured. The negative control $(-$ ve) contains no sample. The positive control contains $0.31 \mu \mathrm{m}$ exogenous cholesterol and demonstrates the accuracy of the assay. The dashed line indicates the limit of detection. $E$, we assessed cholesterol association with WT and mutant CD81. The data are expressed relative to WT CD81, and an asterisk indicates statistical significance from WT ( $n=4$, one-way ANOVA, Prism). The Western blotting demonstrates equivalent levels of CD81 in the whole cell lysate (WCL) and pulldown (IP). F, Huh-7 CD81 KO cells were transduced with lentivectors encoding WT and mutant CD81, and cell-surface expression was confirmed by flow cytometry, as in C. HCV entry was assessed by challenge with a panel of HCVpp (including genotypes 1,2, and 5). HCVpp infection, for three representative clones, is shown relative to cells expressing WT CD81 $(n=4)$. G, summary data displaying mean relative infection, as in $E$, for six HCVpp clones. An asterisk indicates statistical significance from WT (one-way ANOVA, Prism), and error bars indicate the standard deviation of the mean. 
cholesterol. Huh-7 CD81 KO cells transduced with WT CD81 or empty vector control were surface-labeled with anti-CD81 $\mathrm{mAb}$ and then lysed for immunoprecipitation. Following pulldown of CD81-mAb complexes with protein $G$ beads, we assayed the concentration of free, unesterified cholesterol; this is the form of cholesterol found in cellular membranes (49). In the pulldown from cells transduced with empty vector control, we did not measure any free cholesterol, whereas cholesterol was readily detectable in the pulldown from cells expressing WT CD81 (Fig. 1D).

Next, we went on to measure cholesterol association with the binding-pocket mutants; each of the mutants exhibited a reduction in co-immunoprecipitated cholesterol (Fig. 1E). Notably, this experiment cannot discriminate between cholesterol that is directly associated with CD81 and peripheral cholesterol that is indirectly extracted during lysis and immunoprecipitation. Therefore, it is possible that the reduction in cholesterol concentration in each of our mutant pulldowns represents a complete loss of specific cholesterol binding; this, however, cannot be determined. Nonetheless, these data are consistent with specific association between plasma-membrane cholesterol and CD81 and that this interaction can be reduced by mutating residues in the cholesterol-binding pocket of CD81.

We challenged Huh-7 cells expressing each mutant with a panel of $\mathrm{HCV}$ pseudoparticles (HCVpp); these consist of lentiviral reporters pseudotyped with the E1E2 glycoproteins of diverse strains of $\mathrm{HCV}$, as such, this system recapitulates the events of $\mathrm{HCV}$ entry $(50,51)$. Although the various cholesterol pocket mutants possessed identical cellular expression and similar deficiency in cholesterol association (Fig. 1, $C$ and $E$ ), they exhibited differential HCV receptor activity (Fig. 1, F and $G)$. Of the mutations that disrupt hydrogen bond formation with cholesterol, E219Q and N18A/E219A reduced HCV entry by $\sim 50 \%$, whereas the E219A single mutant had equivalent receptor activity to WT CD81. Notably, the V68W/M72W/ A108W/V212W mutant, in which the binding pocket is filled with bulky tryptophan side chains, enhanced HCV entry by $\sim 50 \%$. These data demonstrate that mutations within the cholesterol-binding pocket of CD81 have the capacity to both negatively and positively modulate $\mathrm{HCV}$ entry. However, given that the level of cholesterol association did not correlate with receptor activity, it is unlikely that $\mathrm{HCV}$ is directly dependent on cholesterol occupying the intramembrane-binding pocket of CD81.

\section{SR-B1 does not enhance cholesterol loading into CD81}

CD81 constitutively associates with SR-B1 (7), a cell-surface cholesterol-transporting protein that possesses a central hydrophobic tunnel through which cholesterol can be conveyed from high-density lipoproteins directly to the plasma membrane (52, 53). Moreover, this lipid transport function has been demonstrated to modulate the role of CD81 in HCV and malaria entry $(48,54)$. These observations led us to hypothesize that SR-B1 may directly load cholesterol into the binding cavity of CD81. Indeed, when human SR-B1 is overexpressed in CHO cells, the total cellular cholesterol levels double (Fig. S1A). However, cooverexpression of SR-B1 did not alter CD81-associated choles- terol levels, as assessed by immunoprecipitation (Fig. S1B). This is despite the detection of SR-B1-CD81 complexes in the pulldown. As a further test, we evaluated CD81-cholesterol association in Huh-7 SR-B1 KO cells with and without addback of exogenous SR-B1 (Fig. S1C); we measured no difference in CD81-cholesterol association. Therefore, our data do not support the notion of SR-B1-mediated cholesterol loading of CD81.

\section{Cholesterol regulates conformational switching of CD81}

Zimmerman et al. (26) reported that cholesterol binding regulates a switch in the EC2 of CD81 from a closed conformation (cholesterol-bound) to an open conformation (cholesterolunbound) (Fig. S2). This provides a molecular mechanism by which CD81 may sense cholesterol in cellular membranes. We reasoned that cholesterol sensing, rather than cholesterol binding in and of itself, may provide a mechanism by which the binding-pocket mutants may modulate HCV entry. To investigate this further, we used MD simulation: an in silico methodology for predicting the conformational dynamics of proteins, both at steady state and after perturbations such as ligand removal or mutagenesis $(55,56)$. We conducted five independent 500-ns MD simulations of CD81 with and without cholesterol and quantified the conformational state of the EC2. In the presence of cholesterol, CD81 remained largely in a closed conformation, similar to that seen in the crystal structure, whereas in the absence of cholesterol the EC2 had a propensity to adopt a more extended open conformation. This was particularly apparent in a hinging motion between helix $\mathrm{E}$ of the EC2 and transmembrane domain 4 (TMD4) (Fig. 2A). We therefore quantified the change in angle around this hinge in each simulation, using the angle adopted in the crystal structure as a reference (Fig. $2 B$ ). In the absence of cholesterol, three of five simulations demonstrated clear and sustained extension of the hinge between the EC2 and TMD4. In the presence of cholesterol, the angle of the hinge fluctuated in some simulations but provided little evidence of a persistent conformational switch. To further quantify this we calculated the cumulative time spent in the extended conformation across all five simulations, using an angle of $25^{\circ}$ as a threshold (Fig. 2C). This analysis suggests that, in the absence of cholesterol, CD81 is approximately three times more likely to be found in the open conformation.

In the cholesterol-bound crystal structure of CD81, the hinge between the EC2 and TMD4 is stabilized in a closed conformation by a salt bridge between $\mathrm{Asp}^{196}$ (in helix E of the EC2) and Lys $^{201}$ (at the top of TMD4) (Fig. S2B). Indeed, we observed interaction between these residues during our MD simulations in the presence of cholesterol (Fig. $2 A$, top inset). However, without cholesterol, CD81 adopts the open conformation, in which these residues are orientated on opposite sides of a continuous $\alpha$-helix (Fig. $2 A$, bottom inset). To examine this further, we measured the distance between Asp $^{196}$ and Lys ${ }^{201}$ during each simulation (Fig. 2D). In the presence of cholesterol, the distance between Asp ${ }^{196}$ and Lys ${ }^{201}$ fluctuates; nonetheless they remain in close proximity and frequently reach the short distances $(<10 \AA)$ at which electrostatic interactions and 

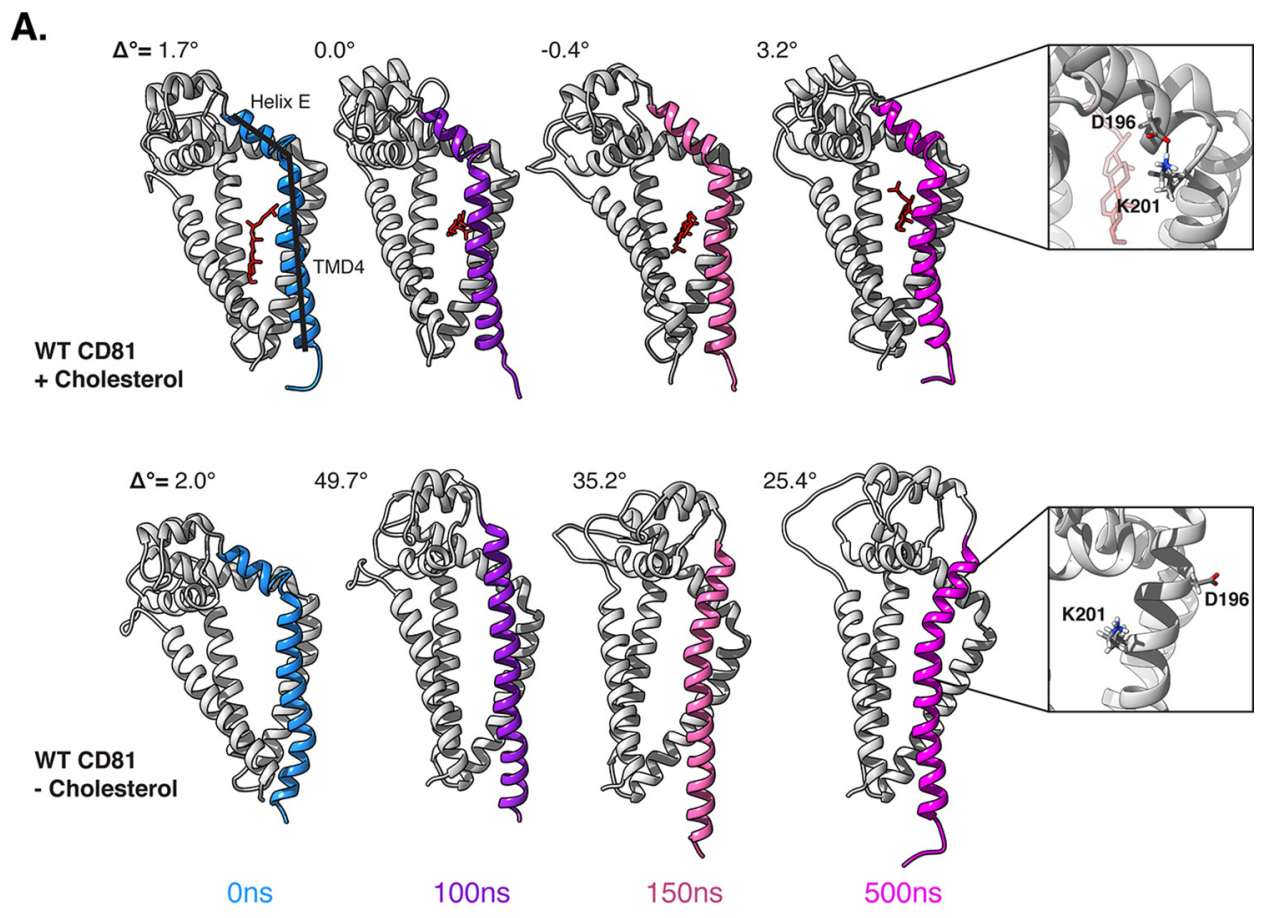

B.

C.
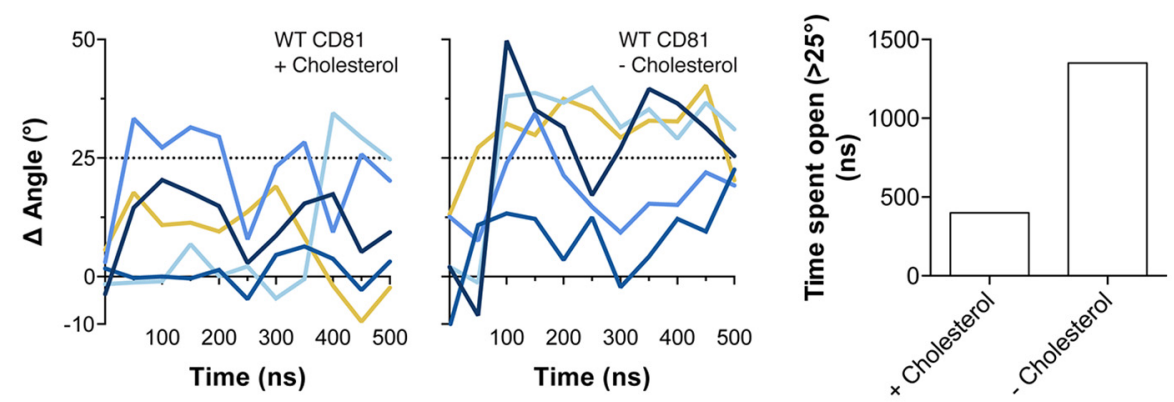

D.
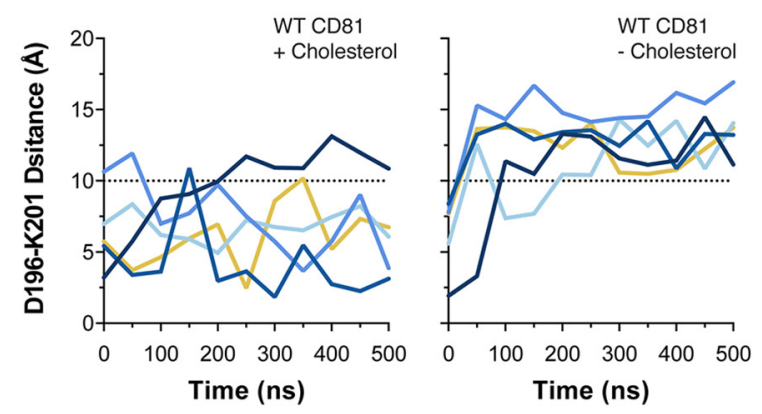

E.

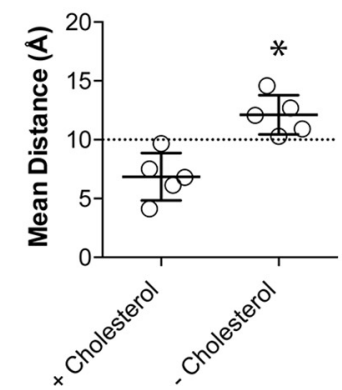

Figure 2. Conformational switching of CD81 in the absence of cholesterol. We performed five independent 500-ns MD simulations of WT CD81 with and without cholesterol. $A$, snapshots summarizing representative simulations from either condition. The $\Delta^{\circ}$ measurement reflects the change in the angle between helix E of the EC2 and TMD4 (as annotated), by comparison with the CD81 crystal structure (Protein Data Bank code 5TCX). For each snapshot the region from which the measurement was taken is color-coded by time. Cholesterol is shown in red. Structures were orientated using TMD4 as a reference. Examples of the orientation of Asp ${ }^{196}$ and Lys ${ }^{201}$ are shown as insets. $B$, the angle between helix E and TMD4 was measured over time for each simulation, and $25^{\circ}$ was chosen as a threshold to indicate conformational switching. $C$, the cumulative time spent in the open conformation was calculated across all simulations for either experimental condition. $D$, the distance between $A \mathrm{sp}^{196}$ and $\mathrm{Lys}^{201}$ was measured over time for each simulation, and the dashed line indicates the distance under which electrostatic interactions and hydrogen bonding occurs ( $10 \AA$ ). E, the average distance between Asp ${ }^{196}$ and Lys $s^{201}$ with and without cholesterol. The data points represent the mean value for each simulation, and the asterisk indicates statistical significance ( $n=5$ simulations, unpaired $t$ test, Prism), and the error bars indicate standard deviation of the mean.

hydrogen bonding can occur (57). By contrast, in the absence of cholesterol, these residues are consistently $>10 \AA$ apart, indicating a change in orientation. To directly compare the experi- mental conditions, we calculated the average distance between $\mathrm{Asp}^{196}$ and $\mathrm{Lys}^{201}$; we found the value to be significantly higher in simulations without cholesterol (Fig. 2E). 
Taken together, these data are consistent with the reports of Zimmerman et al. (26) and support the notion of a cholesteroldependent conformational switch in CD81. Moreover, our MD simulations predict that the absence of cholesterol disrupts stabilizing interactions across the EC2-TMD4 hinge, presumably through allosteric reorientation of amino acid side chains. This relationship provides a potential molecular mechanism for cholesterol sensing by CD81.

\section{Conformational switch mutants modulate HCV entry}

To investigate whether the conformational switch required for CD81 cholesterol sensing is relevant to HCV entry, we mutated both Asp ${ }^{196}$ and $\mathrm{Lys}^{201}$ to alanine, thereby preventing the possibility of interactions between these residues stabilizing the EC2-TMD4 hinge. We would predict that the D196A/ K201A mutant would be more likely to adopt an open conformation, irrespective of the cholesterol binding status of CD81. To test this, we performed five independent MD simulations with the D196A/K201A open mutant in the presence of cholesterol. In line with our expectations, the EC2-TMD4 hinge exhibited persistent opening in two of five simulations; consequently the D196A/K201A was approximately two times more likely to be found in the open state (Fig. 3, $A$ and $B$ ). To further examine the effect of these mutations, we also measured the distance between residues 196 and 201 during the simulations (as in Fig. 2D). In the D196A/K201A open mutant, the residues were consistently $\sim 10 \AA$ apart; this was significantly farther than WT CD81. This would suggest that mutagenesis has successfully prevented stabilizing interactions across the EC2-TMD4. We introduced the CD81 D196A/K201A open mutant into Huh-7 CD81 KO cells and challenged them with HCVpp; the N18A/ E219A cholesterol-binding mutant was also included as a point of comparison (Fig. 3, D and E). D196A/K201A exhibited poor receptor activity for all tested $\mathrm{HCV}$ strains and was statistically indistinguishable from the cholesterol-binding mutant.

The open conformation of CD81 reported by Zimmerman et al. (26) (Fig. S2A) is stabilized by a salt bridge between Lys ${ }^{116}$ and $\mathrm{Asp}^{117}$, which sits around a hinge between helix A of the EC2 and TMD3. We mutated these residues to destabilize the putative open state and, therefore, create a closed mutant of CD81 (Fig. S2C); we tested this alongside the cholesterol binding and open mutants in the HCVpp assay. The K116A/D117A mutant displayed a consistent enhancement of receptor activity (Fig. 3D).

The fact the D196A/K201A open mutant phenocopies the N18A/E219A cholesterol mutant suggests that they both reduce CD81 receptor activity by inducing conformational opening, whereas the opposite effect was observed for the K116A/D117A mutant, which is expected to spend more time in the closed conformation. Therefore, these data support a model in which $\mathrm{HCV}$ entry depends on the cholesterol-mediated closed conformation of CD81.

\section{Residues that contribute to cholesterol sensing are highly conserved}

CD81 is found in all vertebrates, Fig. S3A displays the structure of CD81 color coded for its amino acid conservation across vertebrates; the transmembrane domains and hinge regions of the EC2 display high conservation, whereas the apex of the EC2 exhibits increased diversity. This suggests that the outward-facing apex is under positive selection to drive new interactions and/or to escape pathogen binding (58), whereas the lower region of the protein remains conserved to maintain residues that are essential for basic protein function. If cholesterol sensing and conformational switching are important features of CD81, we may expect high conservation at the residues that regulate these processes. Fig. $\mathrm{S} 3 B$ is a phylogenetic tree constructed from representative vertebrate CD81 protein sequences and annotated to show the degree of conservation observed for the set of mutated residues described above. The residues found in the cholesterol-binding pocket and the conformationswitching residues are all conserved, suggesting functional importance. Notably, the residues at 116, 117, 196, and 201 maintain the potential for salt bridge formation in 15 of 15 and 13 of 15 of the representative sequences; salt bridges often stabilize conformational intermediates of a protein. As a point of comparison we include $\mathrm{Phe}^{186}$, which is presented at the apex of CD81 and is critical for HCV binding $(34,59)$; like much of the EC2, this position exhibits low conservation, consistent with the CD81-dependent species specificity of HCV infection.

\section{CD81 mutants retain normal trafficking and CD19 chaperone function}

CD81 participates in diverse cell biological processes via its interactions with various binding partners (6); for instance, CD81 is critical for B-cell receptor signaling by chaperoning CD19 through the secretory pathway (10-12). Therefore, we evaluated the cellular distribution and chaperone function of the cholesterol-sensing/conformational switch mutants to determine whether this correlated with HCV receptor activity. In all subsequent experiments, as an additional control, we included an F186A mutant that is unable to bind HCV E2 and does not support virus entry $(34,59)$.

When expressed in Huh-7 CD81 KO cells, each of the mutants exhibit equivalent cell-surface expression by flow cytometry (Fig. $4 A$, panel $i$ ) and display no overt changes in cell-surface distribution (Fig. S4A). This suggests that the mutant's receptor activities are not correlated with trafficking deficiencies. To assess chaperone function, we recapitulated CD81-dependent trafficking of CD19 in Huh-7 cells. Fig. S4B displays exogenous CD19 expression in Huh7 cells \pm CD81, as assessed by fluorescence microscopy; no cell-surface CD19 is detectable in Huh-7 CD81 KO cells, despite equivalent total cellular expression of CD19 (Fig. S4C). Fig. $4 A$ (panel ii) displays CD81-dependent cell-surface expression of CD19 in Huh-7 cells. Each of the mutants maintains the ability to chaperone CD19 to the plasma membrane; these data indicate normal cell-surface localization for each of the mutants.

CD81 facilitates HCV entry through interaction with the major viral glycoprotein E2. This can be examined experimentally using soluble E2 glycoprotein ( $\mathrm{sE2}$ ). Although this is the least authentic system available to study HCV entry (sE2 is presented without its partner protein, E1, and not in the context of 
A.

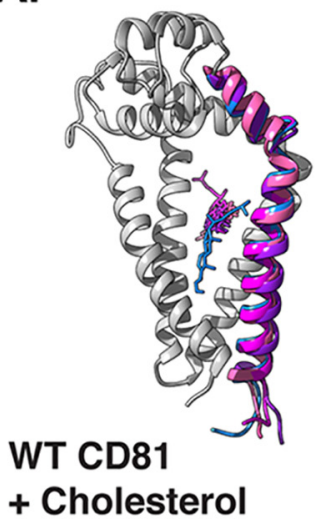

B.

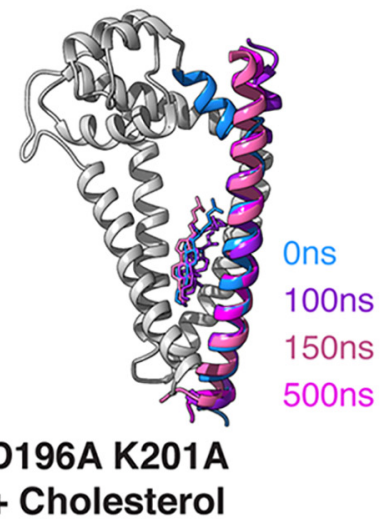

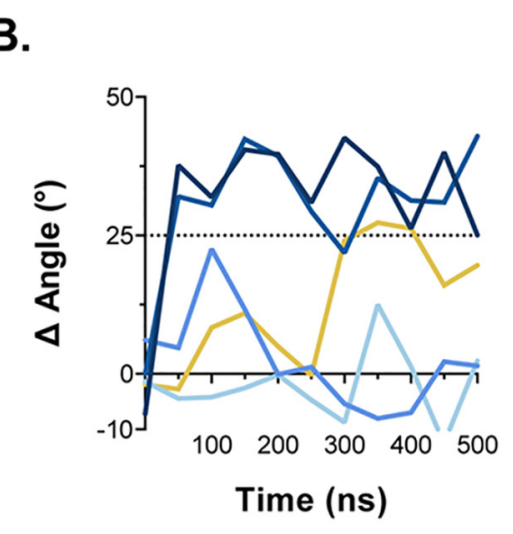

C.

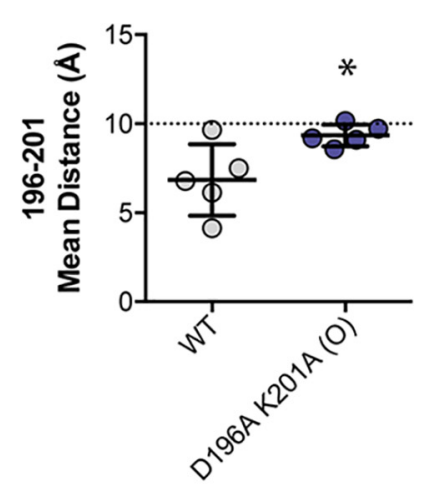

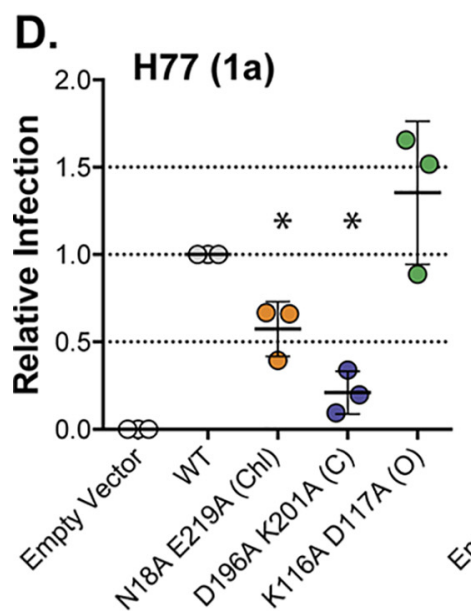
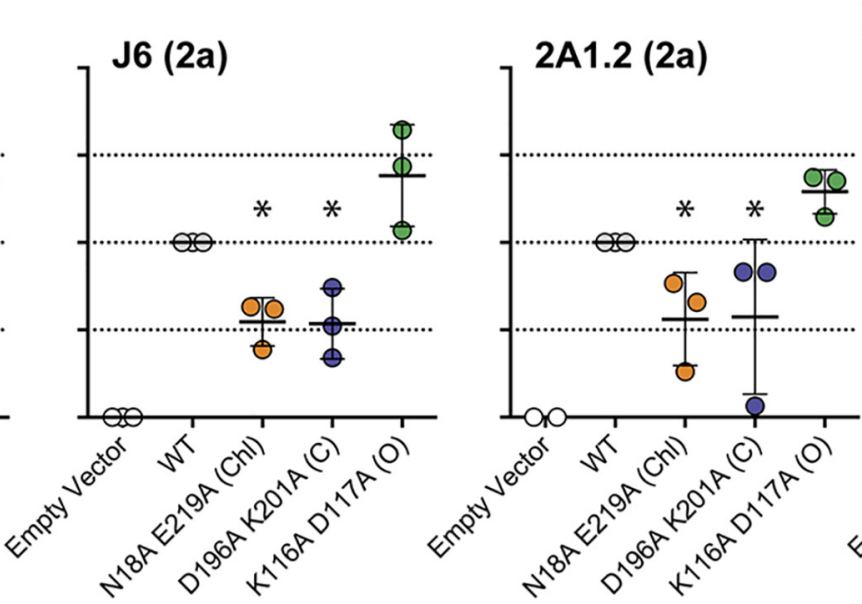

E.

Figure 3. Conformational switch mutants modulate HCV entry. We mutated residues Asp ${ }^{196}$ and Lys ${ }^{201}$ to prevent stabilizing interactions across the EC2TMD4 hinge. A, we performed five independent MD simulations of WT and D196A/K201A CD81 in the presence of cholesterol. Images provide overlaid snapshots from representative simulations. Helix E, TMD4, and cholesterol are color-coded by time. For clarity the remaining structure is shown in gray for the $t=0$ ns snapshot only. Structures were orientated using TMD4 as a reference. $B$, the change in angle between helix E and TMD4, by comparison with the CD81 crystal structure, was measured over time for each D196A/K201A simulation (compare with Fig. 2B). The cumulative time spent in the open conformation across all simulations was $400 \mathrm{~ns}$ for WT and $1050 \mathrm{~ns}$ for D196A/K201A. C, the average distance between residues 196 and 201 for WT and D196A/K201A in the presence of cholesterol. The dashed line indicates the distance under which electrostatic interactions and hydrogen bonding can occur (10 $\AA$ ). The data points represent the mean value for each simulation, and an asterisk indicates statistical significance ( $n=5$ simulations, unpaired $t$ test, Prism). $D$, Huh-7 CD81 KO cells were transduced with lentivectors encoding WT CD81, N18A/E219A (cholesterol-binding mutant), D196A/K201A (open mutant), or K116A/D117A (closed mutant), equal cell-surface expression was confirmed by flow cytometry (representative data are provided in Fig. 4). HCV entry was assessed by challenge with a panel of HCVpp (including genotypes 1, 2, 4, and 5). HCVpp infection, from three representative clones, is shown relative to cells expressing WT CD81. An asterisk indicates statistical significance from WT ( $n=4$, one-way ANOVA, Prism). There was no significant difference between N18A/E219A and D196A/K201A. $E$, summary data displaying mean relative infection, as in $D$, for eight HCVpp clones. An asterisk indicates statistical significance from WT ( $n=8$, one-way ANOVA, Prism). In all plots error bars indicate standard deviation of the mean.

a virion), it is the only tool available to directly assess E2-CD81 interactions at the cell surface.

sE2 binding can be conferred to $\mathrm{CHO}$ cells by introduction of HCV receptors (CD81 or SR-B1) (60). Therefore, we transduced $\mathrm{CHO}$ cells with the CD81 mutants and assessed binding of sE2 from the prototypical J6 and H77 strains. Fig. $4 B$ (panel $i$ ) displays flow cytometry histograms of anti-CD81 $\mathrm{mAb}$ binding to each mutant, demonstrating equivalent $\mathrm{CHO}$ cell-surface expression. Fig. 4B (panel ii) provides representative plots of $\mathrm{J} 6 \mathrm{sE} 2$ binding to $\mathrm{CHO}-\mathrm{CD} 81$ cells; note that although WT CD81 confers robust binding, the F186A mutant displays no interaction with E2. In this context, the N18A/E219A cholesterol and K116A/D117A closed mutants exhibit similar sE2 binding to that of WT CD81, whereas the D196A/K201A open mutant has moderately reduced sE2 binding. This is quantified for both $\mathrm{J} 6$ and $\mathrm{H} 77$ sE2 in Fig. 4C.
These data are not in particularly good agreement with the viral entry levels measured using HCVpp (Fig. 3). Although the low receptor activity of D196A/K201A is somewhat correlated with its ability to bind $\mathrm{sE2}$, there is a disparity in effect sizes: e.g. D196A/K201A exhibits only $\sim 20 \%$ receptor activity for H77 HCVpp (Fig. $3 D$ ) but retains $\sim 80 \%$ binding to H77 sE2 (Fig. 4C). Therefore, although it remains possible that differences in sE2 binding to CD81 mutants may contribute to their ability to support virus entry, it is likely that there is an additional determinant of receptor activity.

\section{CD81 cholesterol sensing is important for infection by authentic HCV}

Although the HCVpp and sE2 experimental systems allow the direct evaluation of HCV entry and receptor interaction, they present the viral glycoproteins in unphysiological 
A.
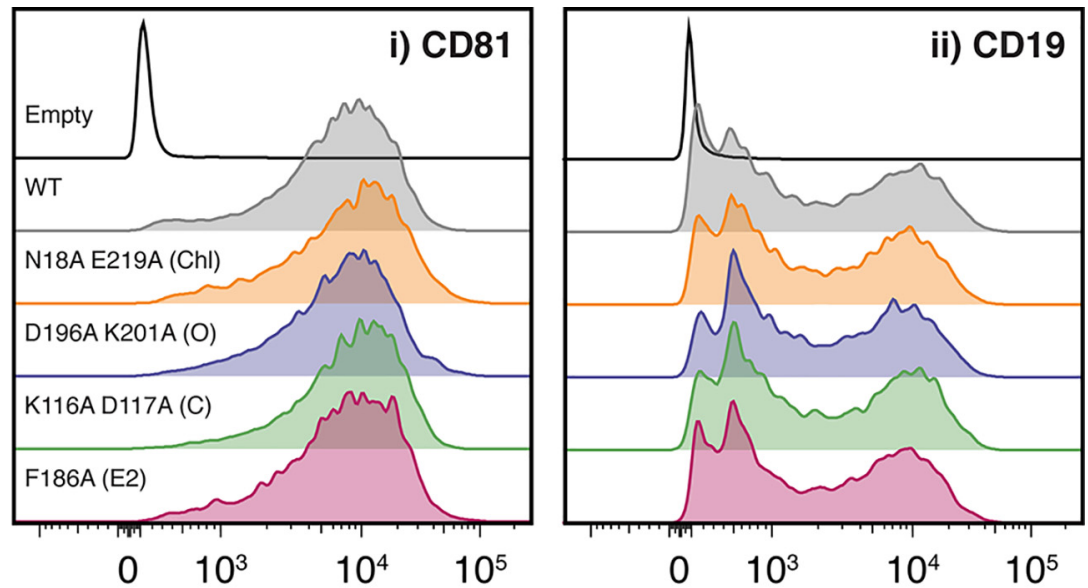

B.
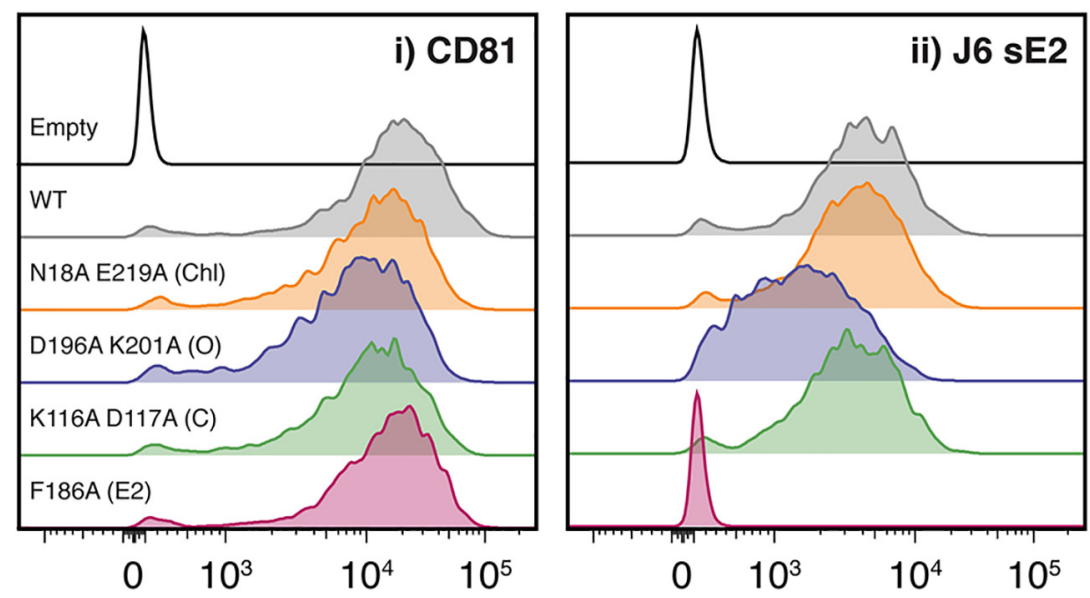

C.

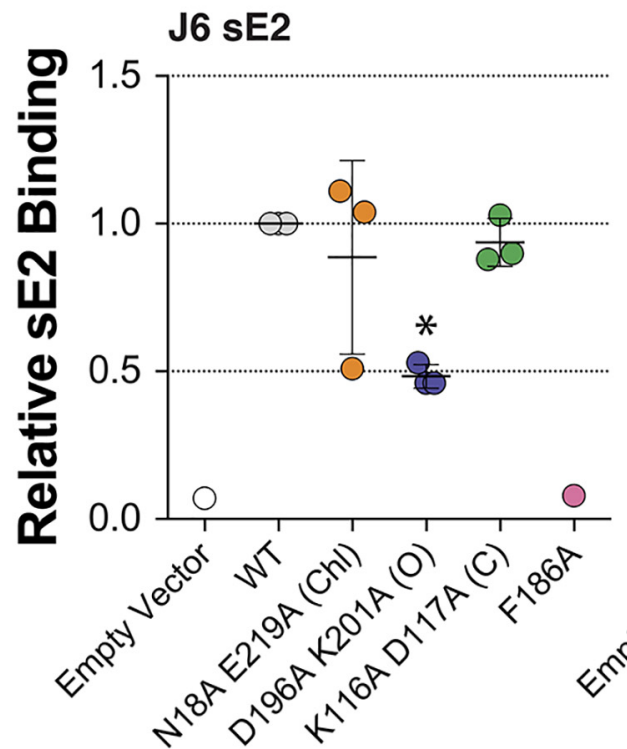

H77 sE2

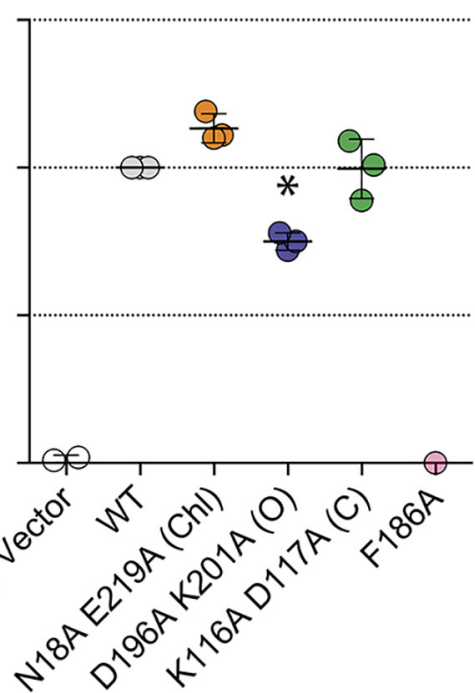

Figure 4. Cell-surface functionality of CD81 mutants. Huh-7 CD81 KO cells were co-transduced with lentivectors encoding human CD19 and CD81 or empty vector. $A$, representative flow cytometry histograms. All samples received CD19 lentivector plus the indicated CD81/control vector. Panel $i$ demonstrates CD81 surface expression, and panel ii displays CD81-dependent trafficking of CD19 to the cell surface. B, CD81 expression on CHO cells confers binding on soluble HCV E2. Panel $i$ demonstrates CD81 surface expression, and panel ii displays sE2 binding to transduced CHO cells. C, quantification of $s E 2$ binding expressed relative to WT CD81. An asterisk indicates statistical significance from WT ( $n=3$, one-way ANOVA, Prism). Error bars indicate standard deviation of the mean.

contexts. Therefore, to complement and corroborate these experiments, we assessed CD81 receptor activity using the $\mathrm{HCV}$ cell culture model (HCVcc); this generates native $\mathrm{HCV}$ particles, which have the unusual property of being enriched in lipids and associated with host lipoprotein components $(36,61-64)$. 
As before, we transduced Huh-7 CD81 KO cells with each of our CD81 mutants and then challenged with J6/JFH HCVcc, quantifying the resultant infection by microscopy. Untransduced cells were completely resistant to $\mathrm{HCV} c$ infection, whereas cells expressing WT CD81 were readily infected (Fig. 5A). Much like the HCVpp system, the N18A/E219A cholesterol-binding mutant and the D196A/K201A open mutant display reduced ability to support HCVcc infection (Fig. 5B). However, in this context the K116A/D117A closed mutant failed to enhance infection, as we observed using HCVpp. The F186A E2 binding mutant exhibited minimal receptor activity. We also challenged CD81-expressing cells with a panel of HCVcc luciferase reporter viruses bearing the glycoproteins of diverse HCV strains from genotypes 1, 2, 3, 4, and 5 (Fig. 5C). These data support our findings with J6/JFH HCVcc: N18A/E219A and D196A/K201A phenocopy each other, being poor receptors for $\mathrm{HCV}$, whereas the K116A/D117A mutant was equivalent to WT CD81. As an additional control we evaluated the effect of mutant CD81 on an $\mathrm{HCV}$ subgenomic replicon (SGR); this is a truncated HCV genome that lacks the structural proteins and, therefore, does not produce virus particles, but allows the processes of HCV translation and genome replication to be studied in isolation (65). In this system the cells expressing CD81, whether WT or mutant, supported JFH-1 SGR replication at a similar level to cells without CD81; this is expected, given that CD81 is thought to act during virus entry. It also demonstrates that the CD81 phenotypes observed using the HCVcc systems cannot be attributed to HCV translation or replication, and must be a consequence of virus entry (Fig. S5). In summary, mutants that alter CD81 cholesterol binding and/or conformational switching are poor receptors for HCVcc particle entry; this demonstrates that cholesterol sensing by CD81 is important for HCV infection.

\section{Conformational switch mutants have altered protein interaction networks}

Like any tetraspanin, the activity of CD81 is defined by its molecular partnerships. Indeed, the interactions of CD81 with SRB1, CLDN1, and EGFR are important for HCV entry, whereas CD81's physiological functions are driven by various other partnerships with, for example, integrins (cell migration) and CD3 (T-cell regulation) $(13,66)$. The molecular mechanisms of tetraspanin-partner interactions remain poorly understood. To investigate the contribution of cholesterol binding and/or conformational switching to CD81's interaction network, we performed co-immunoprecipitation (co-IP) using an anti-CD81 EC2 mAb, followed by label-free quantitative (LFQ) MS on cells expressing CD81 variants. Interaction partners were identified by statistical comparison of LFQ intensities from cells expressing CD81 to control cells without CD81. We identified multiple interacting proteins for WT CD81, consistent with our previous investigations of the CD81 interaction network, including welldescribed partners such as SR-B1 (SCARB1), claudin-1 (CLDN), epidermal growth factor receptor (EGFR), transferrin receptor (TFRC), calpain-5 (CAPN5), integrin $\beta-1$ (ITGB1), and CD151 (Fig. $6 A$ and File $S 1$ ). Fig. $6 B$ displays enrichment values for these aforementioned proteins in co-IP/MS analyses of CD81 expressing versus control cells $(7,8)$. Intensity values were similar for most of these selected proteins, suggesting comparable interactions with WT and mutant CD81. Moreover, interactions with reported HCV entry factors (SR-B1, claudin-1, EGFR, transferrin receptor, and calpain-5 (8, 67-70)) were not correlated to receptor activity. For example, EGFR association was reduced for both the D196A/K201A (open) and K116A/D117A (closed) mutants (Fig. 6A, Fig. S6, and File S1). Nonetheless, these mutants have opposing activities in the infectivity assays (Figs. 3 and 5), suggesting that EGFR interaction is not a determinant of these phenotypes. In addition to this focused analysis of well-described interaction partners, we also compared the entire interaction network for each of the CD81 mutants (Fig. 6C). The cholesterol-binding mutant (N18A/E219A) was largely unchanged, with $>90 \%$ of interactions maintained. In contrast, the conformational switch mutants exhibit a 40-50\% loss of interactions; cross-comparison revealed a degree of polarization between these mutants, suggesting the loss of different subsets of partnerships. These data suggest that the EC2 of CD81 is important for partner interactions, as has been recently demonstrated for CD19 (71). Moreover, the conformation of the EC2 (either open or closed) may regulate protein network assembly. However, this experiment did not provide evidence of cholesterol-mediated regulation of partnerships, and we were unable to identify specific interaction(s) that correlated with $\mathrm{HCV}$ receptor activity.

\section{Discussion}

Like many tetraspanins, CD81 partners with a variety of cellsurface components to contribute to various physiological and pathological processes $(5,6)$. The CD81 crystal structure solved by Zimmerman et al. (26) provided a new perspective on tetraspanin biology and proposed two novel features that may be highly relevant for protein function: (i) CD81 is able to bind cholesterol in a cavity formed by its transmembrane domains and (ii) the EC2 of CD81 undergoes a cholesterol-dependent conformational switch between a compact closed form to an extended open configuration. These properties bestow CD81 with a potential cholesterol-sensing mechanism; this is particularly interesting given the long-standing link between tetraspanin biology and cholesterol $(7,27,28)$.

How cholesterol sensing contributes to CD81 function was, thus far, unclear. In this study, we investigated these structural features in the context of a well-characterized biological activity: CD81's ability to mediate HCV entry. The importance of our work is 2-fold; it provides a greater understanding of the molecular basis of CD81 cholesterol sensing and also demonstrates that these features are important for CD81's ability to support HCV infection.

First we mutated residues within the cholesterol-binding pocket of CD81 (Fig. 1); these mutations were designed to either directly prevent CD81-cholesterol interaction or to fill the binding pocket with bulky side chains, therefore negating cholesterol binding. We demonstrated co-immunoprecipitation of CD81 and free cholesterol. This is good evidence of association between CD81 and plasma membrane-resident cholesterol. We observed a significant reduction in cholesterol association for each of our binding-pocket mutants; this supports the notion of specific retention of cholesterol in CD81. However, 
A.

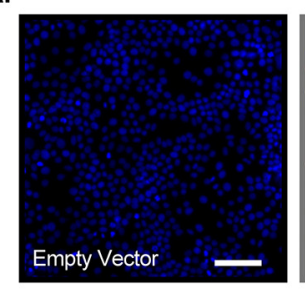

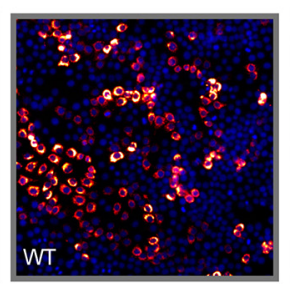

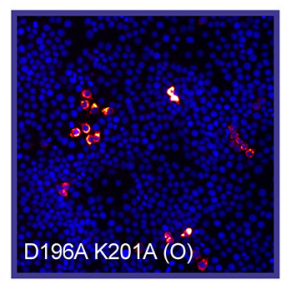

B.

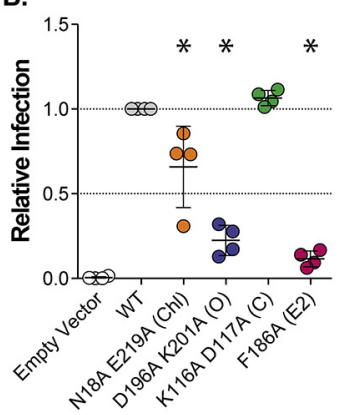

D.

C.
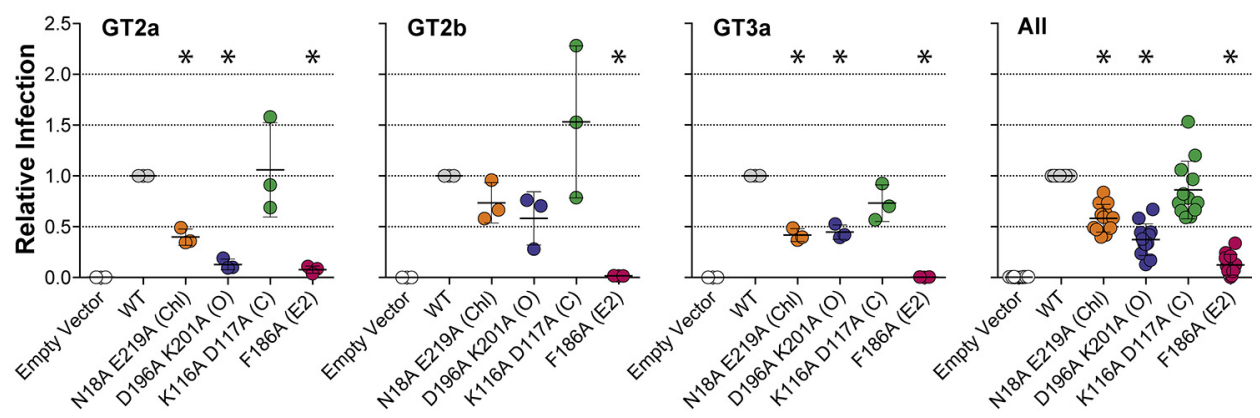

Figure 5. Cholesterol sensing is important for authentic HCV infection. Huh-7 CD81 KO cells were transduced with lentivectors expressing the stated CD81 mutants and were then challenged with J6/JFH HCVcc. Equal cell-surface expression of WT and mutant CD81 was confirmed by flow cytometry (representative data are provided in Fig. 4). A, representative micrographs of HCVcc infection in transduced cells. The 4',6-diamino-2-phenylindole nuclei shown in blue, and viral antigen NS5A is displayed in orange. Scale bar, $100 \mu \mathrm{m}$. B, quantification of infection. The data are expressed relative to infection in cells expressing WT CD81, and an asterisk indicates statistical significance from WT ( $n=4$, one-way ANOVA, Prism). $C$, Huh-7 Lunet N cells stably expressing the stated CD81 mutants were challenged with a panel of diverse HCVcc bearing the glycoproteins of genotypes 1, 2, 3, 4, and 5. Infection was quantified via a virally encoded luciferase reporter and is shown, relative to WT CD81, for three representative clones. An asterisks indicates statistical significance from WT ( $n=3$, one-way ANOVA, Prism). D, summary data displaying mean relative infection, as in C, for $12 \mathrm{HCV} c \mathrm{c}$ chimeras. An asterisk indicates statistical significance from WT ( $n=12$ one-way ANOVA, Prism). In all plots, error bars indicate standard deviation of the mean.

cholesterol association did not reach background levels; this may indicate some nonspecific association (caused by detergent extraction) or that the mutations were insufficient to completely prevent capture of cholesterol.

Despite their equivalent deficiency in cholesterol association, the binding-pocket mutants had disparate activity in the HCVpp assay, being either neutral (E219A), detrimental (E219Q and N18A/E219A), or beneficial (V68W/M72W/A108W/V212W) to $\mathrm{HCV}$ entry. This suggests that receptor activity is not determined directly by the ability to bind cholesterol and may, instead, be dependent on the molecular/structural consequences of cholesterol binding. Interestingly, the enhancement of $\mathrm{HCV}$ entry by the V68W/M72W/A108W/V212W mutant (and its phenotypic similarity to the K116A/D117A closed mutant) may indicate that filling the binding pocket of CD81 with bulky side chains, in fact, mimics cholesterol binding.

Following these experiments we hypothesized that cholesterol sensing, with its associated conformational change (26), may underpin the relationship between the cholesterol-binding pocket and $\mathrm{HCV}$ entry. To investigate this further we performed MD simulations of CD81 conformational dynamics; these experiments shed light on the potential molecular mechanisms of CD81 cholesterol sensing. In particular we observed a hinging motion between the EC2 and TMD4 of CD81 that was more likely to occur in the absence of cholesterol (Fig. 2). Furthermore, in the CD81 crystal structure (which includes cholesterol), this hinge is conformationally locked in the closed orien- tation by a salt bridge between Asp ${ }^{196}$ and Lys ${ }^{201}$. By measuring the distance between Asp ${ }^{196}$ and Lys ${ }^{201}$ throughout the simulations, we demonstrated that in the absence of cholesterol, these residues are reorientated such that stabilizing interactions are unlikely to occur. Therefore, we propose that cholesterol sensing occurs through allosteric regulation of the EC2-TMD4 hinge.

To test this potential mechanism we mutated the residues necessary for these stabilizing interactions (Fig. 3). The D196A/ K201A mutant performed as expected under MD simulation: conformational switching occurred more frequently than WT CD81 despite the presence of cholesterol in the binding pocket. The D196A/K201A mutant also had poor receptor activity in the HCVpp system and was phenotypically indistinguishable from the N18A/E219A cholesterol-binding mutant. Furthermore, we designed an additional mutant (K116A/D117A) that, based on the work of Zimmerman et al. (26), is predicted to destabilize the open conformation of CD81; therefore, K116A/ D117A can be considered as being opposite to the D196A/ K201A. This closed mutant of CD81 exhibited enhanced HCV receptor activity and appeared to be phenotypically similar to the mutant with the filled cholesterol pocket (V68W/M72W/ A108W/V212W).

The results of these experiments can be reconciled with a potential model of CD81 cholesterol sensing and HCV infection. In its cholesterol-bound state, CD81 is in a closed conformation; it is this form of CD81 that is active for HCV entry. 

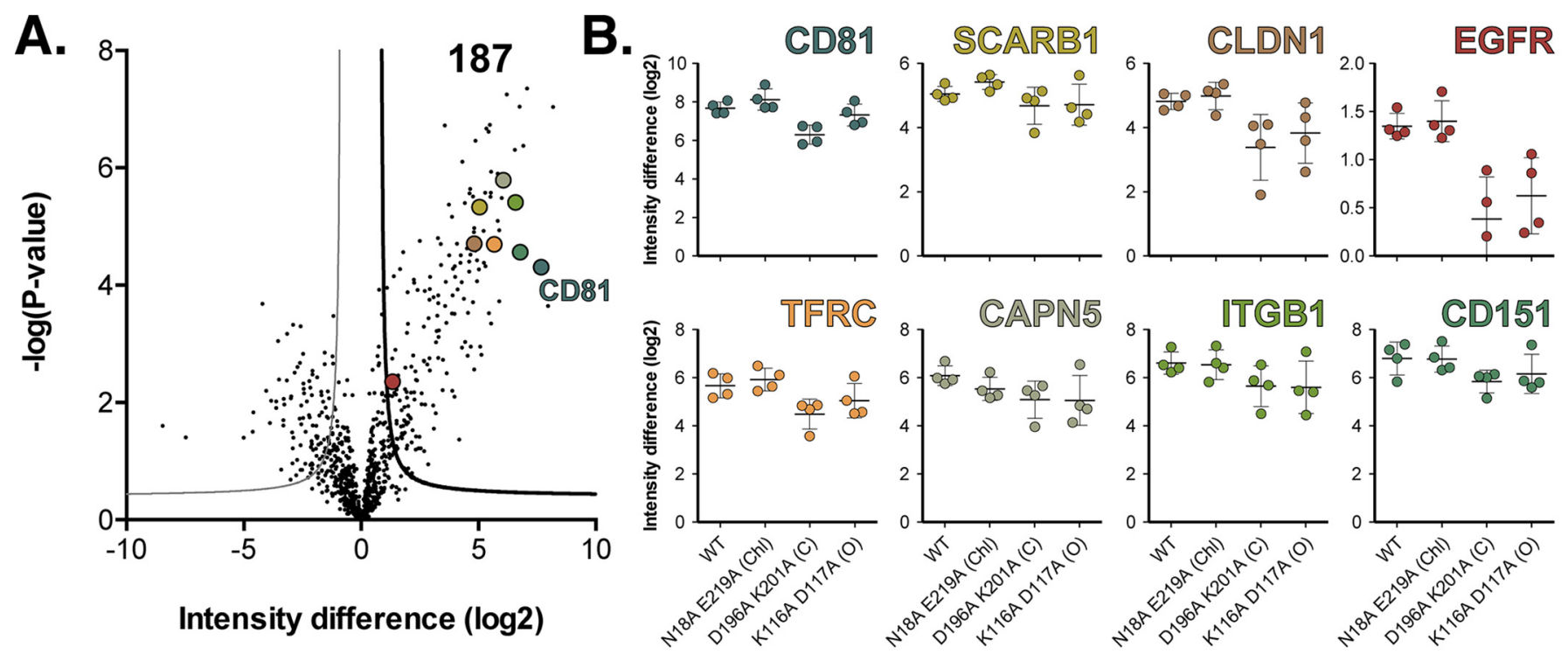

C.

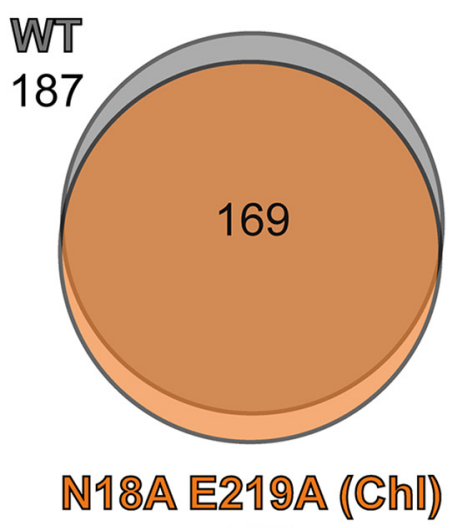

187

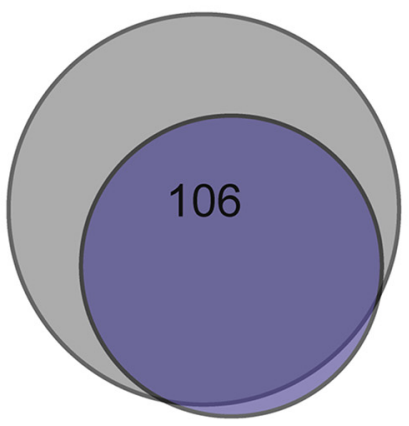

D196A K201A (O) 111

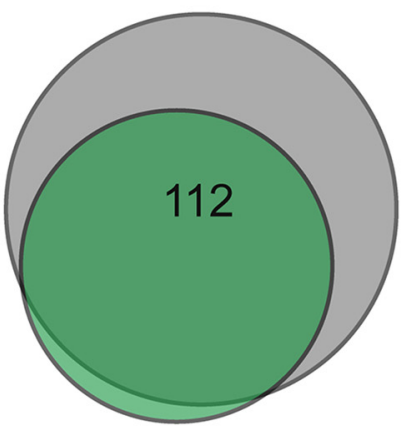

K116A D117A(C) 119

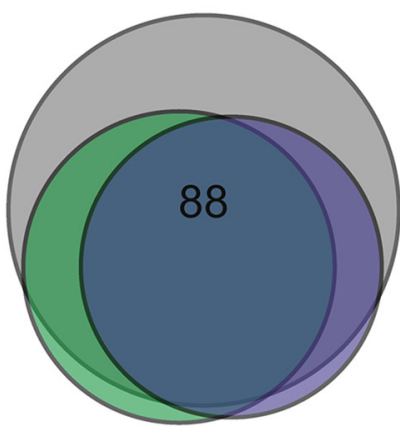

K116A D117A (C) D196A K201A (O)

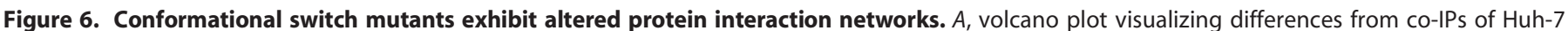

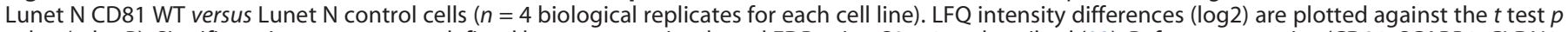

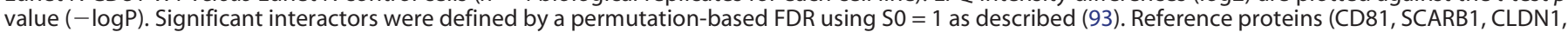

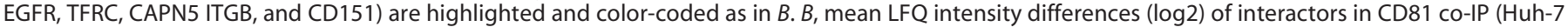

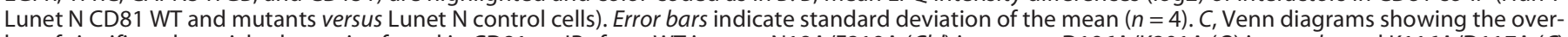

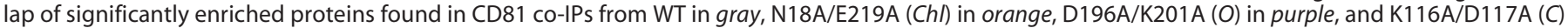

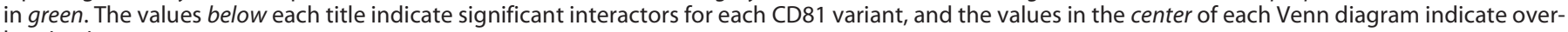
lapping interactors.

Conversely, conformational opening of CD81 in the absence of cholesterol reduces its receptor activity. Therefore, bindingpocket mutants may modulate $\mathrm{HCV}$ entry by dysregulating cholesterol sensing: the E219Q and N18A/E219A mutants reduce $\mathrm{HCV}$ entry by reducing cholesterol retention, whereas the V68W/M72W/A108W/V212W enhances entry by mimicking cholesterol occupancy of the binding pocket. In this framework, the open and closed mutants act by decoupling conformational switching from cholesterol binding. The E219A mutant was neutral in the HCVpp assay; this is less consistent with the above model. However, our work suggests that cholesterol binding regulates CD81 conformation through an allosteric reorientation of the EC2-TMD4 hinge. Therefore, it is possible that the E219A mutant has a compensatory effect that prevents allosteric reorientation in the absence of choles- terol and therefore retains $\mathrm{HCV}$ receptor activity. Each of the mutated residues exhibit very high levels of conservation (Fig. S3), which is consistent with their being necessary for an essential function, such as cholesterol sensing.

We used the HCVcc system to test the mutants in a more physiologically relevant setting. The results of these experiments were largely consistent with the HCVpp entry assay (Fig. 5) with one notable exception: the K116A/D117A closed mutant did not enhance HCVcc infection. This disparity is most likely attributable to the fundamental differences between the constituents of HCVpp and HCVcc particles, the latter being associated with host lipoprotein components and enriched for host-derived lipids, including cholesterol $(62-64,72)$. This may suggest that the lipoprotein-like properties of native HCV particles allow them to modulate CD81 cholesterol sensing. 
CD81 participates in a variety of cell biological processes through its interactions with myriad binding partners. We used co-IP and LFQ MS to characterize the interaction networks of the cholesterol-sensing mutants (Fig. 6). The conformational switch mutants (both open and closed) exhibited reduced interactions. This is consistent with the notion that the EC2 is responsible for binding partnerships and CD81 oligomerization $(71,73,74)$; moreover, these data may suggest that EC2 conformation regulates protein network assembly. Notably, both the open and closed mutants demonstrated reduced interactions with known HCV co-factors (EGFR and, to a lesser extent, Claudin-1; Fig. 6B). This observation does not correlate well with virus entry data; the closed mutant (K116A/D117A) has robust receptor activity, despite reduced co-factor interactions. (Figs. 3-5). Therefore, either co-factor interactions remain sufficient for HCV entry, or the closed mutant's potential enhancing activity (Fig. 3) overcomes any deleterious effect from loss of interactions. Mutations to reduce cholesterol binding (N18A/E219A) had a negligible effect on the interactome of CD81. This may indicate that cholesterol binding/sensing is inconsequential for CD81 interactions, although it is also possible that residual retention of cholesterol (Fig. 1) is sufficient to allow normal partnership interactions. In summary the relationship between cholesterol sensing, protein interactions, and $\mathrm{HCV}$ receptor activity remains obscure and will require further investigation.

We did not determine why HCV entry may favor the closed conformation of CD81. We found no differences in the trafficking or cell-surface distribution of mutant CD81, only the D196A/K201A mutant exhibited any alteration in interaction with sE2 (Fig. 4), and the interaction networks of the various mutants were not predictive of $\mathrm{HCV}$ receptor activity (Fig. 6). Nonetheless, one might speculate on alternative mechanisms by which EC2 conformation determines receptor activity. For instance the close physical proximity of the closed EC2 to the plasma membrane may be beneficial. A recent report of the structure of HIV-1 gp120 in complex with its co-receptor CCR5 suggests that the principal role of CCR5 is to anchor the HIV fusion machinery in close apposition to the host membrane (63); consequently the HIV fusion peptide is within striking distance upon activation. CD81 has been implicated in HCV fusion (64) and has a low profile at the cell surface, particularly in the closed conformation; therefore, it could perform an analogous anchoring function for the HCV glycoproteins. Under this mechanism, the open conformation of CD81 may generate an insurmountable gap between the viral and host membranes, inhibiting fusion and, therefore, entry.

Notably, SR-B1 funnels cholesterol from its lipoprotein ligands directly into the plasma membrane $(52,75)$. Moreover, it is well-established that HCV entry is enhanced by lipoproteins and that HCV particles themselves are lipoprotein-like, being highly enriched for cholesterol $(62-64,72,76)$. Therefore, we hypothesized that local delivery of cholesterol via SRB1 may regulate CD81 function. However, co-overexpression of SR-B1 did not enhance cholesterol association with CD81 (Fig. S1); this was observed in CHO cells and Huh-7 SR-B1 KO cells. Therefore, our data do not support this hypothesis. Nonetheless, it remains possible that physiological sources of exoge- nous cholesterol, for example lipoproteins, could trigger CD81 cholesterol sensing; this requires further investigation.

This study did not identify a physiological function of CD81 that is affected by cholesterol sensing; for example, CD19 trafficking was unaltered (Fig. 4). Nonetheless, it is worth considering how cholesterol sensing may occur in the context of CD81's natural cellular environment. The lipid milieu within distinct subcellular membranes is tightly regulated to impart different biophysical and functional properties (77). For example, whereas the plasma membrane is enriched for free cholesterol, intracellular membranes (e.g. endoplasmic reticulum and Golgi apparatus) have 5-10-fold lower cholesterol content. Therefore, newly synthesized CD81 travels along a cholesterol concentration gradient as it passes through the secretory pathway to the plasma membrane; consequently cholesterol sensing is likely to occur most frequently at the cell surface. This provides a potential mechanism for regulating CD81 function in a location-dependent manner. Moreover, the cell surface does not present a homogenous lipid environment; phase separation results in microdomains enriched for different lipid species, including cholesterol (49). Cell-surface proteins segregate within these lipid microdomains, and this can alter protein function $(78,79)$. It is possible that cholesterol sensing determines CD81 function in a microdomain-specific manner; indeed, there is evidence that CD81 can transition in and out of cholesterol-dependent lipid domains at the cell surface $(28,47)$. Therefore, cholesterol sensing may allow CD81 to respond to dynamic changes in the local lipid environment; how this might affect CD81's physiological and pathological activities will be the focus of future research efforts.

\section{Experimental procedures}

\section{Cell culture}

Huh-7 CD81 KO, and SR-B1 KO, cells were a kind gift from Prof. Yoshiharu Matsuura (Osaka University, Osaka, Japan) (37). Huh-7.5 cells were acquired from Apath LLC. Huh-7 Lunet $\mathrm{N}$ cells were generated as previously described (80). HEK293T and CHO-K1 cells were acquired from the American Type Culture Collection. All cells were grown at $37^{\circ} \mathrm{C}$ in Dulbecco's modified Eagle's medium supplemented with $10 \%$ fetal calf serum, $1 \%$ nonessential amino acids and 1\% penicillin/ streptomycin.

\section{Antibodies}

Anti-NS5 and anti-CD81 mAbs were a kind gift from Prof. Jane McKeating (University of Oxford, Oxford, UK). The anti-CD81 mAbs have been described in detail recently (35). Anti-CD19 (sc-19650) was purchased from Santa Cruz Biotechnology. StrepMAb classic was purchased from IBA GmbH (Göttingen, Germany). All secondary antibodies purchased from Thermo Fisher Scientific.

\section{Lentiviral vectors}

Commercially synthesized gene sequences encoding WT and mutant CD81 were inserted into lentiviral expression 
plasmids by restriction digest. CD19 was cloned into the same background through PCR amplification from human cDNA. These plasmids will be made freely available after publication: https://www.addgene.org/Joe_Grove/. To generate lentiviral vectors HEK293T cells were co-transfected with pCMV-dR8.91 packaging construct, pMD2.G VSV-G expression plasmid and one of each of the CD81 encoding plasmids. Supernatants containing viral vectors were collected at 48 and $72 \mathrm{~h}$. The transduction efficiency of vectors were titrated by flow cytometry to allow equivalent transduction and expression of CD81 variants.

\section{HCV pseudoparticles}

HCVpp were generated in a similar manner to the lentiviral expression vectors. HEK293T cells were co-transfected with pCMV-dR8.91 packaging construct, a luciferase reporter plasmid and an expression vector encoding the appropriate $\mathrm{HCV}$ glycoprotein. Supernatants containing HCVpp were collected at 48 and $72 \mathrm{~h}$. UKN4.1.1, 5.2.1, 2A1.2 and 2B1.1 E1E2 expression plasmids were kindly provided by Alex Tarr and Jonathan Ball (University of Nottingham, UK), all other E1E2 plasmids were generated in-house through PCR or commercial gene synthesis.

\section{HCVCC}

HCVcc were generated as described previously (36). Briefly, in vitro transcribed full-length HCV RNA genomes were electroporated into Huh-7.5 cells. Supernatants containing infectious HCVcc were harvested every $2-4 \mathrm{~h}$ during the day, from 3 to 7 days postelectroporation. The harvests were then pooled, aliquoted, and frozen to generate a standardized stock for infection assays.

\section{Infections}

Huh-7 or Huh-7 Lunet $\mathrm{N}$ cells were seeded into 96-well plates $24 \mathrm{~h}$ prior to the experiment; to infect they were challenged with HCVpp/HCVcc supernatants (diluted $1 / 2$ to $1 / 4$ in Dulbecco's modified Eagle's medium, $6 \%$ fetal calf serum). The infections were allowed to proceed for $72 \mathrm{~h}$ before readout. For HCVpp, the samples were lysed and assayed using the SteadyGlo reagent kit and a GloMax luminometer (Promega, Maddison, WI, USA). To measure HCVcc replication, the cells were fixed with $100 \%$ methanol and stained for viral NS5 protein, the proportion of infected cells was determined using the ImageJ Infection Counter plugin (81), and these data were also verified by manually counting foci forming units. For HCVcc encoding a Renilla luciferase reporter, the cells were lysed with Milli-Q water and frozen at $-80{ }^{\circ} \mathrm{C}$ to ensure complete lysis, the samples were transferred to 96-well white plates and mixed with Renilla luciferase substrate solution (Coelenterazine, $0.42 \mathrm{mg} /$ $\mathrm{ml}$ in methanol), and luciferase activity was determined using a microplate reader Centro XS (Berthold Technologies, Harpenden, UK).

\section{Subgenomic replicon system}

SGR transcripts were generated by in vitro transcription and introduced into target cells by electroporation (as with HCVcc).
Replication was assessed at 4 and 24 h postelectroporation by readout of a genetically encoded Renilla luciferase reporter, as described above.

\section{Flow cytometry}

To measure cell-surface expression of CD81 or CD19, singlecell suspensions of Huh-7/CHO cells were fixed in 1\% formaldehyde and then blocked in PBS $+1 \%$ BSA. All subsequent steps are performed in blocking buffer. The cells $(100 \mu \mathrm{l}$ at $1-$ $3 \times 10^{6} / \mathrm{ml}$ ) were then serially incubated with anti-receptor antibodies followed by anti-mouse Alexa Fluor 647 secondary, $1 \mathrm{~h}$ of incubation each at room temperature. Fluorescence signals were measured on a LSR Fortessa (BD, Franklin Lakes, NJ, USA), and the data were analyzed using FlowJo (FlowJo LLC, Ashland, OR, USA). The lentiviral vectors, described above, also express GFP (from a separate promoter); therefore, this GFP signal was used as an independent measure of transduction to identify positive cells during analysis.

\section{Immunoprecipitation and cholesterol association assay}

Huh7 CD81 KO cells were transduced to express various CD81 cholesterol-binding mutants. To perform the pulldown, a confluent $T 150 \mathrm{~cm} 2$ flask of cells were trypsinized, harvested, and resuspended in "traffic stop" buffer, PBS + 1\% BSA and $0.01 \%$ sodium azide; this depletes cellular ATP pools, consequently preventing receptor internalization (60). The resuspended cells were then incubated with anti-CD81 mAb 2.131 at $1 \mu \mathrm{g} / \mathrm{ml}$ for $60 \mathrm{~min}$. The cells were washed with PBS and then lysed in 1\% Brij58 buffer (1\% Brij58, $20 \mathrm{~mm}$ Tris, pH 7.5, 150 $\mathrm{mm} \mathrm{NaCl}, 1 \mathrm{mM} \mathrm{CaCl}_{2}, 1 \mathrm{~mm} \mathrm{MgCl}_{2}$, and $0.02 \% \mathrm{NaN}_{3}$ ) plus $1 \times$ protease inhibitor for $30 \mathrm{~min}$. All steps were carried out on ice. The lysates were centrifuged at $13,300 \mathrm{rpm}$ for $12 \mathrm{~min}$ at $4{ }^{\circ} \mathrm{C}$ and then incubated with protein G-Sepharose beads for 90 min on a tube rotator in the cold room. Finally, the beads were washed and stored at $-20^{\circ} \mathrm{C}$ in $1 \%$ Brij58 buffer until further analysis.

We quantified cholesterol associated with CD81 using an Amplex Red cholesterol assay (Thermo Fisher Scientific). The beads were pelleted by centrifugation, resuspended in $1 \times$ reaction buffer (as described by the manufacturer), and incubated in a tube rotator at room temperature for $15 \mathrm{~min}$; this step extracts cholesterol associated with the immunocomplexes. The beads were then centrifuged, and the supernatant was diluted by half in $1 \times$ reaction buffer to a total volume of $50 \mu \mathrm{l}$. The samples were incubated with $50 \mu \mathrm{l}$ of working solution of Amplex Red reagent at $37^{\circ} \mathrm{C}$; cholesterol esterase was omitted from the CD81 samples to ensure the measurement of freecholesterol only. Signal was measured using the fluorescence plate reading capability of a real-time PCR machine (Bio-Rad). A standard curve was prepared through serial dilution of the cholesterol reference in $1 \times$ reaction buffer, allowing the concentration of cholesterol to be determined in the positive control and CD81 samples.

\section{Western blotting}

One day prior to the study, Huh-7 cells \pm CD81 and/or CD19 were seeded into standard 24-well plates at $4 \times 10^{4}$ cells/ 
well. The cells were then lysed using a buffer containing $20 \mathrm{~mm}$ Tris- $\mathrm{HCl}, 135 \mathrm{~mm} \mathrm{NaCl}, 1 \%$ Triton X-100, and 10\% glycerol. The samples were then run on a TruPage 4-12\% gel under nonreducing conditions and transferred on to nitrocellulose membrane. The blots were blocked in PBS $+2 \%$ milk solution + $0.1 \%$ Tween 20 and then probed by serial incubation with antireceptor antibodies and goat anti-mouse secondary conjugated to horseradish peroxidase. Chemiluminescence signal was then measured in a Chemidoc MP (Bio-Rad).

\section{Microscopy}

One day prior to study, Huh-7 cells \pm CD81 and/or CD19 were seeded into standard 24 -well plates at $1.2 \times 10^{4}$ cells/well. The cells were then fixed (in situ) in $2 \%$ formaldehyde, blocked, and stained, as described for flow cytometry, with the inclusion of a 10-min 4',6-diamino-2-phenylindole counterstain at the end of the procedure. The samples were imaged on a Nikon $\mathrm{Ti}$ inverted microscope, through a $40 \times$ extra-long working distance objective, using a C2 confocal scan head with 405- and 635-nm laser illumination (Nikon Instruments, Tokyo, Japan). Multiple Z-stacks were acquired for each sample. The data were processed for display using FIJI/ImageJ $(82,83)$.

\section{Soluble E2 binding assay}

J6 and H77 E2 ectodomains (residues 384-661) were PCRcloned into expression vectors, as previously described (60), with the resultant constructs including an upstream tissue plasminogen activator signal sequence (to direct efficient secretion) and a downstream Strep-tag II (for detection and purification). The proteins were produced by transient transfection of HEK293T cells with the supernatants being harvested at 48 and $72 \mathrm{~h}$ postinfection. sE2 was purified using a Strep-Tactin column (IBA Life Sciences, Göttingen, Germany), and monomeric sE2 was subsequently isolated by size exclusion chromatography. The sE2 binding assay was performed as previously described. A single-cell suspension of $\mathrm{CHO} \pm$ CD81 cells were preincubated in "traffic stop" buffer, described above. All subsequent steps are performed in traffic stop buffer. The cells (100 $\mu \mathrm{l}$ at $\left.1-3 \times 10^{6} / \mathrm{ml}\right)$ were then mixed with $10 \mu \mathrm{g} / \mathrm{ml} \mathrm{sE} 2$ and incubated for $1 \mathrm{~h}$ at $37^{\circ} \mathrm{C}$. Bound sE2 was then detected using $3 \mu \mathrm{g} / \mathrm{ml}$ StrepMab classic followed by an anti-mouse Alexa Fluor 647 secondary ( $1 \mathrm{~h}$ of incubation each at room temperature). Finally, the cells were fixed in $1 \%$ formaldehyde. Fluorescence signals were measured by flow cytometry.

\section{Co-immunoprecipitation and LC-MS/MS analysis}

To identify CD81 interaction partners, Huh-7 Lunet N cells expressing CD81 (WT or mutant) or empty vector control were harvested from a $90 \%$ confluent $\mathrm{T} 150 \mathrm{~cm} 2$ plate by scraping. The experiments were conducted in four biological replicates from four independent cell passages. The cells were lysed in Brij58 buffer (1\% Brij 58, $50 \mathrm{~mm}$ Hepes, pH 7.4, $150 \mathrm{~mm}$ $\mathrm{NaCl}, 10 \%$ glycerol, $1 \mathrm{~mm} \mathrm{CaCl} \mathrm{m}_{2}$ ) supplemented with $1 \times$ protease and phosphatase inhibitors for $30 \mathrm{~min}$ on ice. Nuclear debris was pelleted at $12,000 \times g$ for $10 \mathrm{~min}$ at $4{ }^{\circ} \mathrm{C}$ followed by co-immunoprecipitation using Pierce cross-link immunoprecipitation kit (Thermo Fisher Scientific) with cross-linked anti-
CD81 (clone 1.3.3.22, Santa Cruz). The efficiency of bait enrichment was determined by Western blotting using antiCD81 (JS-81, BD Biosciences).

The co-IP samples were reduced, alkylated, and trypsinized as previously described (7). Peptide mixtures were analyzed using a nanoflow LC-MS/MS on an EASY-nLC 1000 system (Thermo Fisher Scientific) coupled to a Q Exactive HF-X quadrupole Orbitrap mass spectrometer (Thermo Fisher Scientific). A column oven (Sonation) maintained the temperature at $60{ }^{\circ}$ C. 500-ng peptide samples in buffer A (0.1\% formic acid) were loaded onto a $50-\mathrm{cm}$ column with $75-\mu \mathrm{m}$ inner diameter, packed with C18 1.9- $\mu$ m ReproSil beads (Dr. Maisch GmbH). The peptides were separated chromatographically with a 95 min gradient from $5 \%$ to $30 \%$ buffer B (80\% acetonitrile, $0.1 \%$ formic acid).

The MS was operated in data-dependent acquisition mode, where one full scan $(300-1650 \mathrm{~m} / z, r=60,000$ at $200 \mathrm{~m} / \mathrm{z})$ at a target of $3 \times 10^{6}$ ions is followed by 15 data-dependent MS/MS scans with higher energy collisional dissociation (target $10^{5}$ ions; maximum ion fill time, $28 \mathrm{~ms}$; isolation window, $1.4 \mathrm{~m} / \mathrm{z}$; normalized collision energy, 27\%; $r=15000$ at $200 \mathrm{~m} / \mathrm{z}$ ). Dynamic exclusion of $30 \mathrm{~s}$ was enabled.

MS raw files were processed in MaxQuant (version 1.6.2.0 (84)), and peptide fragment lists were searched against the human FASTA Uniprot reference proteome (June 2019; 20,415 entries without isoforms (UP000005640) and 42411 with isoforms (UP000005640(1))) by the built-in Andromeda search engine. We restricted enzyme specificity with cleavage C-terminal to Lys or Arg (trypsin and Lys-C), allowing up to two missed cleavages. Precursor mass tolerance was set to $20 \mathrm{ppm}$, and fragment mass tolerance was set to $4.5 \mathrm{ppm}$. Fixed modifications of cysteine carbamidomethylation and variable modifications for the $\mathrm{N}$-acetylation of proteins and the oxidation of methionine were specified. The minimum peptide length was set to seven amino acids. False discovery rates (FDRs) at the peptide and protein levels were $1 \%$. The label-free-quantification (MaxLFQ) and matching between runs features were enabled.

Protein groups were filtered for decoys, contaminants, and modifications. The data were also filtered for valid values (three, in at least one group). Protein identification data are provided in File S2. Interaction profiles were analyzed with imputation of missing values (width, 0.3; down shift, 1.8). Statistical analysis of proteomics data were conducted using two-sample $t$ test comparing LFQ intensities of proteins found in CD81 WT or mutants, against empty vector control (FDR, 0.05; s0, 1). The resulting protein interactions have been submitted to the IMEx Consortium (RRID:SCR_002805) through IntAct (85) with the assigned identifier IM-28053. The MS proteomics data have been deposited to the ProteomeXchange Consortium via the PRIDE partner repository (86) with the data set identifier PXD019260.

\section{Molecular dynamics simulations}

We started with a molecular model of full-length CD81 in a closed conformation; this is based on the crystal structure (Protein Data Bank code 5TCX), as previously described, and was 


\section{CD81 cholesterol sensing}

generously provided by Prof. Ron O. Dror and Dr. Brendan Kelly. All substitutions were introduced using Modeller software and AutoSub.py script available at https://github.com/ williamdlees/AmberUtils. Protonation states were determined in MolProbity (87). There are three histidine residues (at positions 37, 151, and 191) within the CD81. In the models of WT without cholesterol and D196A/K201A with cholesterol, all histidines were protonated on the $\epsilon$ nitrogen. In the WT with cholesterol model, the histidines 37 and 191 were also protonated on the $\epsilon$ nitrogen, and the histidine 151 was protonated on the $\delta$ nitrogen. Models were then inserted into simulated palmitoyl-oleoyl-phosphatidylcholine (POPC) bilayers using CHARMM-GUI $(87,88)$.

For MD simulations, each variant model was put through the same pipeline. First, the models were solvated in a rectangular box using TIP3 water molecules and $0.15 \mathrm{M}$ of $\mathrm{NaCl}$. The volume of the box was $\sim 5 \times 10^{5} \AA^{3}$ with the total of $\sim 5.2 \times 10^{4}$ atoms including $\sim 128$ lipid molecules. The CHARMM 36 force field was used for the simulations on GPUs using the CUDA version of PMEMD in Amber 18 (89-91). The systems were minimized by 2500 steps of steepest descent followed by 2500 steps of the conjugate gradient method with all protein atoms restrained by a force of $10 \mathrm{kcal} / \mathrm{mol} / \AA^{2}$ and phosphate atoms of the POPC bilayer by a force of $2.5 \mathrm{kcal} / \mathrm{mol} / \AA^{2}$. The systems were then heated to $310 \mathrm{~K}$ for $25 \mathrm{ps}$ using the Langevin thermostat under constant volume while keeping the identical restraints, followed by further 25 ps with the protein atoms restrained by $5 \mathrm{kcal} / \mathrm{mol} / \AA^{2}$ and the phosphate atoms of the POPC bilayer by a force of $2.5 \mathrm{kcal} / \mathrm{mol} / \AA^{2}$. Initial velocities were sampled from Boltzmann distribution.

Further equilibration was performed under constant pressure ( 1 bar) using the Monte Carlo barostat and semi-isotropic pressure coupling for 25 ps with the protein atoms restrained by $2.5 \mathrm{kcal} / \mathrm{mol} / \AA^{2}$ and the phosphate atoms of the POPC bilayer by a force of $1 \mathrm{kcal} / \mathrm{mol} / \AA^{2}$. This was followed by additional three equilibration steps lasting 100 ps each under constant pressure using the Monte Carlo barostat and semi-isotropic pressure coupling with the protein atoms decreasing to $1,0.5$, and $0.1 \mathrm{kcal} / \mathrm{mol} / \AA^{2}$ and the phosphate atom restraints decreasing to $0.5,0.1$ and 0 restraints $\mathrm{kcal} / \mathrm{mol} / \AA^{2}$, respectively.

Following minimization and equilibration steps, 500 -ns production runs were simulated under constant pressure using the Monte Carlo barostat, semi-isotropic pressure coupling, and constant temperature via the Langevin thermostat at $310 \mathrm{~K}$. For each independent simulation the restart file from the final equilibration step was used as the input for a short (1 ns) production run, but only the coordinates, not the velocity, were used to decorrelate the simulation. The coordinates from this short run were then used as input for the 500-ns production run.

A 1-fs time step was used for minimization, and the first two equilibration steps. SHAKE was used to restrain hydrogen bonds in all but the minimization steps, and 2-fs time step was used for the last four equilibration and production runs. For all simulations, the cutoff distance for Lennard-Jones 6-12 interactions was set to be $12 \AA$. The Lennard-Jones $6-12$ were smoothed over the range of 10-12 $\AA$ using the force-based switching function. Particle mesh Ewald method was used for the long-range electrostatic interactions, and 1-4 nonbonded interactions were not scaled. To avoid the overflow of coordinates, the iwrap was set to 1 .

\section{Sequence conservation analysis}

Vertebrate CD81 encoding gene sequences were pulled from the NCBI database. Multiple sequence alignment and phylogenetic tree construction (using representative gene sequences) was performed using a CLC sequence viewer (Qiagen).

\section{Molecular modeling}

Molecular graphics and analyses performed with UCSF Chimera, developed by the Resource for Biocomputing, Visualization, and Informatics at the University of California, San Francisco, with support from National Institutes of Health Grant P41-GM103311 (92).

\section{Statistical analysis}

All statistical analysis was performed in GraphPad Prism 6.0 (San Diego, CA, USA). Ordinary one-way ANOVA was performed using Dunnett's multiple comparison test, using WT CD81 as a control, unless stated otherwise. Unpaired $t$ test was performed assuming equal standard deviation using a two-tailed $p$ value.

\section{Data availability}

The raw MS proteomics data have been deposited to the ProteomeXchange Consortium PXD019260. The protein interaction results are available from IMEx: https://www.ebi.ac.uk/ intact/pages/interactions/interactions.xhtml?query=pubid: IM-28053.

Acknowledgments-We are grateful to Prof. Jane McKeating for reagents and advice. Thank you to Prof. Greg Towers and Mphatso Kalemera for scientific criticism. Thanks to Dr. Michael Tomlinson for technical advice on immunoprecipitation of tetraspanins. Also, thank you to Nicole Finardi for efforts on the project.

Author contributions-M. P., L. S., P. M., A. L., M. P. A., J. K., R. M., and S. E. investigation; M. P. methodology; L. S., A. L., S. E., and J. G. formal analysis; L. S. funding acquisition; F. M., G. G., A. J. S., and J. G. supervision; G. G. and J. G. conceptualization; J. G. visualization; J. G. writing-original draft; J. G. project administration.

Funding and additional information-J. G. is supported by Sir Henry Dale Fellowship 107653/Z/15/Z from the Wellcome Trust and Royal Society. L. S. received Wellcome Trust Ph.D. Studentship 109162/Z/15/Z. G. G. was funded by the Knut and Alice Wallenberg Foundation, Deutsche Forschungsgemeinschaft Projektnummer 158989968-SFB 900 Project C7, and Deutsche Forschungsgemeinschaft Project GE 2145/3-2. This work was also supported by funds from the German Academic Exchange Service (to J. K.); the Master Program Infection Biology, Alemania, Argentina (AMIBA) and the 'Centro Universitario Argentino-Alemán'-Deutsch Argentinisches Hochschulzentrum' (CUAA-DAHZ) (to M. P. A.); and the Infection Biology International Ph.D. Program of Hannover Biomedical Research School (to R. M.). 
Conflict of interest-The authors declare that they have no conflicts of interest with the contents of this article.

Abbreviations - The abbreviations used are: $\mathrm{HCV}$, hepatitis $\mathrm{C}$ virus; PDB, Protein Data Bank; MD, molecular dynamics; HCVpp, HCV pseudoparticle(s); TMD, transmembrane domain; HCVcc, HCV cell culture model; SGR, subgenomic replicon; IP, immunoprecipitation; LFQ, label-free quantitative; EGFR, epidermal growth factor receptor; FDR, false discovery rate; POPC, palmitoyl-oleoyl-phosphatidylcholine; ANOVA, analysis of variance.

\section{References}

1. Pileri, P., Uematsu, Y., Campagnoli, S., Galli, G., Falugi, F., Petracca, R., Weiner, A. J., Houghton, M., Rosa, D., Grandi, G., and Abrignani, S. (1998) Binding of hepatitis C virus to CD81. Science 282, 938-941 CrossRef Medline

2. Kinchen, V. J., Zahid, M. N., Flyak, A. I., Soliman, M. G., Learn, G. H., Wang, S., Davidson, E., Doranz, B. J., Ray, S. C., Cox, A. L., Crowe, J. E., Jr., Bjorkman, P. J., Shaw, G. M., and Bailey, J. R. (2018) Broadly neutralizing antibody mediated clearance of human hepatitis $C$ virus infection. Cell Host Microbe 24, 717-730.e5 CrossRef Medline

3. Flyak, A. I., Ruiz, S., Colbert, M. D., Luong, T., Crowe, J. E., Jr., Bailey, J. R., and Bjorkman, P. J. (2018) HCV broadly neutralizing antibodies use a CDRH3 disulfide motif to recognize an E2 glycoprotein site that can be targeted for vaccine design. Cell Host Microbe 24, 703-716.e3 CrossRef Medline

4. Banse, P., Moeller, R., Bruening, J., Lasswitz, L., Kahl, S., Khan, A. G., Marcotrigiano, J., Pietschmann, T., and Gerold, G. (2018) CD81 receptor regions outside the large extracellular loop determine hepatitis $C$ virus entry into hepatoma cells. Viruses 10, 207 CrossRef Medline

5. Charrin, S., Jouannet, S., Boucheix, C., and Rubinstein, E. (2014) Tetraspanins at a glance. J. Cell Sci. 127, 3641-3648 CrossRef Medline

6. Charrin, S., Le Naour, F., Silvie, O., Milhiet, P.-E., Boucheix, C., and Rubinstein, E. (2009) Lateral organization of membrane proteins: tetraspanins spin their web. Biochem. J. 420, 133-154 CrossRef Medline

7. Gerold, G., Meissner, F., Bruening, J., Welsch, K., Perin, P. M., Baumert, T. F., Vondran, F. W., Kaderali, L., Marcotrigiano, J., Khan, A. G., Mann, M., Rice, C. M., and Pietschmann, T. (2015) Quantitative proteomics identifies serum response factor binding protein 1 as a host factor for hepatitis C virus entry. Cell Rep. 12, 864-878 CrossRef Medline

8. Bruening, J., Lasswitz, L., Banse, P., Kahl, S., Marinach, C., Vondran, F. W., Kaderali, L., Silvie, O., Pietschmann, T., Meissner, F., and Gerold, G. (2018) Hepatitis C virus enters liver cells using the CD81 receptor complex proteins calpain-5 and CBLB. PLoS Pathog. 14, e1007111 CrossRef Medline

9. van Zelm, M. C., Smet, J., Adams, B., Mascart, F., Schandené, L., Janssen, F., Ferster, A., Kuo, C.-C., Levy, S., van Dongen, J. J. M., and van der Burg, M. (2010) CD81 gene defect in humans disrupts CD19 complex formation and leads to antibody deficiency. J. Clin. Invest. 120, 1265-1274. CrossRef Medline

10. Cherukuri, A., Shoham, T., Sohn, H. W., Levy, S., Brooks, S., Carter, R., and Pierce, S. K. (2004) The tetraspanin CD81 is necessary for partitioning of coligated CD19/CD21-B cell antigen receptor complexes into signaling-active lipid rafts. J. Immunol. 172, 370-380 CrossRef Medline

11. Shoham, T., Rajapaksa, R., Boucheix, C., Rubinstein, E., Poe, J. C., Tedder, T. F., and Levy, S. (2003) The tetraspanin CD81 regulates the expression of CD19 during B cell development in a postendoplasmic reticulum compartment. J. Immunol. 171, 4062-4072 CrossRef Medline

12. Mattila, P. K., Feest, C., Depoil, D., Treanor, B., Montaner, B., Otipoby, K. L., Carter, R., Justement, L. B., Bruckbauer, A., and Batista, F. D. (2013) The actin and tetraspanin networks organize receptor nanoclusters to regulate B cell receptor-mediated signaling. Immunity 38, 461-474 CrossRef Medline

13. Rocha-Perugini, V., Zamai, M., González-Granado, J. M., Barreiro, O., Tejera, E., Yañez-Mó, M., Caiolfa, V. R., and Sanchez-Madrid, F. (2013)
CD81 controls sustained T cell activation signaling and defines the maturation stages of cognate immunological synapses. Mol. Cell Biol. 33, 36443658 CrossRef Medline

14. Brimacombe, C. L., Wilson, G. K., Hübscher, S. G., McKeating, J. A., and Farquhar, M. J. (2014) A role for CD81 and hepatitis C virus in hepatoma mobility. Viruses 6, 1454-1472 CrossRef Medline

15. Diao, J., Pantua, H., Ngu, H., Komuves, L., Diehl, L., Schaefer, G., and Kapadia, S. B. (2012) Hepatitis C virus induces epidermal growth factor receptor activation via CD81 binding for viral internalization and entry. J. Virol. 86, 10935-10949 CrossRef Medline

16. Rubinstein, E., Ziyyat, A., Prenant, M., Wrobel, E., Wolf, J.-P., Levy, S., Le Naour, F., and Boucheix, C. (2006) Reduced fertility of female mice lacking CD81. Dev. Biol. 290, 351-358 CrossRef Medline

17. Ohnami, N., Nakamura, A., Miyado, M., Sato, M., Kawano, N., Yoshida, K., Harada, Y., Takezawa, Y., Kanai, S., Ono, C., Takahashi, Y., Kimura, K., Shida, T., Miyado, K., and Umezawa, A. (2012) CD81 and CD9 work independently as extracellular components upon fusion of sperm and oocyte. Biol. Open. 1, 640-647 CrossRef Medline

18. Jin, Y., Takeda, Y., Kondo, Y., Tripathi, L. P., Kang, S., Takeshita, H., Kuhara, H., Maeda, Y., Higashiguchi, M., Miyake, K., Morimura, O., Koba, T., Hayama, Y., Koyama, S., Nakanishi, K., et al. (2018) Double deletion of tetraspanins CD9 and CD81 in mice leads to a syndrome resembling accelerated aging. Sci. Rep. 8, 5145 CrossRef Medline

19. Schinzel, R. T., Higuchi-Sanabria, R., Shalem, O., Moehle, E. A., Webster, B. M., Joe, L., Bar-Ziv, R., Frankino, P. A., Durieux, J., Pender, C., Kelet, N., Kumar, S. S., Savalia, N., Chi, H., Simic, M., et al. (2019) The hyaluronidase, TMEM2, promotes ER homeostasis and longevity independent of the UPRER. Cell 179, 1306-1318.e18 CrossRef Medline

20. Nydegger, S., Khurana, S., Krementsov, D. N., Foti, M., and Thali, M. (2006) Mapping of tetraspanin-enriched microdomains that can function as gateways for HIV-1. J. Cell Biol. 173, 795-807 CrossRef Medline

21. He, J., Sun, E., Bujny, M. V., Kim, D., Davidson, M. W., and Zhuang, X. (2013) Dual function of CD81 in influenza virus uncoating and budding. PLoS Pathog. 9, e1003701 CrossRef Medline

22. Shaw, M. L., Stone, K. L., Colangelo, C. M., Gulcicek, E. E., and Palese, P. (2008) Cellular proteins in influenza virus particles. PLoS Pathog. 4, e1000085 CrossRef Medline

23. Grove, J. (2014) Super-resolution microscopy: a virus' eye view of the cell. Viruses 6, 1365-1378 CrossRef Medline

24. Rocha-Perugini, V., Suárez, H., Álvarez, S., López-Martín, S., Lenzi, G. M., Vences-Catalán, F., Levy, S., Kim, B., Muñoz-Fernández, M. A., SánchezMadrid, F., and Yáñez-Mó, M. (2017) CD81 association with SAMHD1 enhances HIV-1 reverse transcription by increasing dNTP levels. Nat. Microbiol. 2, 1513-1522 CrossRef Medline

25. Silvie, O., Rubinstein, E., Franetich, J.-F., Prenant, M., Belnoue, E., Rénia, L., Hannoun, L., Eling, W., Levy, S., Boucheix, C., and Mazier, D. (2003) Hepatocyte CD81 is required for Plasmodium falciparum and Plasmodium yoelii sporozoite infectivity. Nat. Med. 9, 93-96 CrossRef Medline

26. Zimmerman, B., Kelly, B., McMillan, B. J., Seegar, T. C. M., Dror, R. O., Kruse, A. C., and Blacklow, S. C. (2016) Crystal structure of a full-length human tetraspanin reveals a cholesterol-binding pocket. Cell 167, 10411051.e11 CrossRef Medline

27. Charrin, S., Manié, S., Thiele, C., Billard, M., Gerlier, D., Boucheix, C., and Rubinstein, E. (2003) A physical and functional link between cholesterol and tetraspanins. Eur. J. Immunol. 33, 2479-2489 CrossRef Medline

28. Silvie, O., Charrin, S., Billard, M., Franetich, J.-F., Clark, K. L., van Gemert, G.-J., Sauerwein, R. W., Dautry, F., Boucheix, C., Mazier, D., and Rubinstein, E. (2006) Cholesterol contributes to the organization of tetraspaninenriched microdomains and to CD81-dependent infection by malaria sporozoites. J. Cell Sci. 119, 1992-2002 CrossRef Medline

29. Drummer, H. E., Boo, I., Maerz, A. L., and Poumbourios, P. (2006) A conserved Gly436-Trp-Leu-Ala-Gly-Leu-Phe-Tyr motif in hepatitis $C$ virus glycoprotein E2 is a determinant of CD81 binding and viral entry. J. Virol. 80, 7844-7853 CrossRef Medline

30. Drummer, H. E., Wilson, K. A., and Poumbourios, P. (2005) Determinants of CD81 dimerization and interaction with hepatitis $C$ virus glycoprotein E2. Biochem. Biophys. Res. Commun. 328, 251-257 CrossRef Medline 


\section{CD81 cholesterol sensing}

31. Drummer, H. E., Wilson, K. A., and Poumbourios, P. (2002) Identification of the hepatitis $C$ virus $\mathrm{E} 2$ glycoprotein binding site on the large extracellular loop of CD81. J. Virol. 76, 11143-11147 CrossRef Medline

32. Keck, Z.-Y., Saha, A., Xia, J., Wang, Y., Lau, P., Krey, T., Rey, F. A., and Foung, S. K. H. (2011) Mapping a region of hepatitis C virus E2 that is responsible for escape from neutralizing antibodies and a core CD81-binding region that does not tolerate neutralization escape mutations. J. Virol. 85, 10451-10463 CrossRef Medline

33. Kong, L., Giang, E., Nieusma, T., Kadam, R. U., Cogburn, K. E., Hua, Y., Dai, X., Stanfield, R. L., Burton, D. R., Ward, A. B., Wilson, I. A., and Law, M. (2013) Hepatitis C virus E2 envelope glycoprotein core structure. Science 342, 1090-1094 CrossRef Medline

34. Higginbottom, A., Quinn, E. R., C., Kuo, C., Flint, M., Wilson, L. H., Bianchi, E., Nicosia, A., Monk, P. N., McKeating, J. A., and Levy, S. (2000) Identification of amino acid residues in CD81 critical for interaction with hepatitis C virus envelope glycoprotein E2. J. Virol. 74, 36423649 CrossRef Medline

35. Grove, J., Hu, K., Farquhar, M. J., Goodall, M., Walker, L., Jamshad, M., Drummer, H. E., Bill, R. M., Balfe, P., and McKeating, J. A. (2017) A new panel of epitope mapped monoclonal antibodies recognising the prototypical tetraspanin CD81. Wellcome Open Res. 2, 82 CrossRef Medline

36. Lindenbach, B. D., Evans, M. J., Syder, A. J., Wölk, B., Tellinghuisen, T. L., Liu, C. C., Maruyama, T., Hynes, R. O., Burton, D. R., McKeating, J. A., and Rice, C. M. (2005) Complete replication of hepatitis $C$ virus in cell culture. Science 309, 623-626 CrossRef Medline

37. Yamamoto, S., Fukuhara, T., Ono, C., Uemura, K., Kawachi, Y., Shiokawa, M., Mori, H., Wada, M., Shima, R., Okamoto, T., Hiraga, N., Suzuki, R., Chayama, K., Wakita, T., and Matsuura, Y. (2016) Lipoprotein receptors redundantly participate in entry of hepatitis C virus. PLoS Pathog. 12, e1005610 CrossRef Medline

38. Flint, M., von Hahn, T., Zhang, J., Farquhar, M., Jones, C. T., Balfe, P., Rice, C. M., and McKeating, J. A. (2006) Diverse CD81 proteins support hepatitis C virus infection. J. Virol. 80, 11331-11342 CrossRef Medline

39. Fofana, I., Xiao, F., Thumann, C., Turek, M., Zona, L., Tawar, R. G., Grunert, F., Thompson, J., Zeisel, M. B., and Baumert, T. F. (2013) A novel monoclonal anti-CD81 antibody produced by genetic immunization efficiently inhibits Hepatitis C virus cell-cell transmission. PLoS One 8, e64221 CrossRef Medline

40. Koutsoudakis, G., Herrmann, E., Kallis, S., Bartenschlager, R., and Pietschmann, T. (2007) The level of CD81 cell surface expression is a key determinant for productive entry of hepatitis $\mathrm{C}$ virus into host cells. J. Virol. 81, 588-598 CrossRef Medline

41. Zhang, J., Randall, G., Higginbottom, A., Monk, P., Rice, C. M., and McKeating, J. A. (2004) CD81 is required for hepatitis C virus glycoprotein-mediated viral infection. J. Virol. 78, 1448-1455 CrossRef Medline

42. Owsianka, A., Tarr, A. W., Juttla, V. S., Lavillette, D., Bartosch, B., Cosset, F.-L., Ball, J. K., and Patel, A. H. (2005) Monoclonal antibody AP33 defines a broadly neutralizing epitope on the hepatitis $C$ virus E2 envelope glycoprotein. J. Virol. 79, 11095-11104 CrossRef Medline

43. Sabo, M. C., Luca, V. C., Prentoe, J., Hopcraft, S. E., Blight, K. J., Yi, M., Lemon, S. M., Ball, J. K., Bukh, J., Evans, M. J., Fremont, D. H., and Diamond, M. S. (2011) Neutralizing monoclonal antibodies against hepatitis $\mathrm{C}$ virus $\mathrm{E} 2$ protein bind discontinuous epitopes and inhibit infection at a postattachment step. J. Virol. 85, 7005-7019 CrossRef Medline

44. Giang, E., Dorner, M., Prentoe, J. C., Dreux, M., Evans, M. J., Bukh, J., Rice, C. M., Ploss, A., Burton, D. R., and Law, M. (2012) Human broadly neutralizing antibodies to the envelope glycoprotein complex of hepatitis $\mathrm{C}$ virus. Proc. Natl. Acad. Sci. U.S.A. 109, 6205-6210 CrossRef Medline

45. Harris, H. J., Davis, C., Mullins, J. G. L., Hu, K., Goodall, M., Farquhar, M. J., Mee, C. J., McCaffrey, K., Young, S., Drummer, H., Balfe, P., and McKeating, J. A. (2010) Claudin association with CD81 defines hepatitis C virus entry. J. Biol. Chem. 285, 21092-21102 CrossRef Medline

46. Ding, Q., von Schaewen, M., and Ploss, A. (2014) The impact of hepatitis C virus entry on viral tropism. Cell Host Microbe 16, 562-568 CrossRef Medline

47. Yalaoui, S., Huby, T., Franetich, J.-F., Gego, A., Rametti, A., Moreau, M., Collet, X., Siau, A., van Gemert, G.-J., Sauerwein, R. W., Luty, A. J. F., Vaillant, J.-C., Hannoun, L., Chapman, J., Mazier, D., et al. (2008) Scavenger receptor BI boosts hepatocyte permissiveness to Plasmodium infection. Cell Host Microbe 4, 283-292 CrossRef Medline

48. Rodrigues, C. D., Hannus, M., Prudêncio, M., Martin, C., Gonçalves, L. A., Portugal, S., Epiphanio, S., Akinc, A., Hadwiger, P., Jahn-Hofmann, K., Röhl, I., van Gemert, G.-J., Franetich, J.-F., Luty, A. J. F., Sauerwein, R., et al. (2008) Host scavenger receptor SR-BI plays a dual role in the establishment of malaria parasite liver infection. Cell Host Microbe 4, 271-282 CrossRef Medline

49. Maxfield, F. R., and van Meer, G. (2010) Cholesterol, the central lipid of mammalian cells. Curr. Opin. Cell Biol. 22, 422-429 CrossRef Medline

50. Bartosch, B., Dubuisson, J., and Cosset, F.-L. (2003) Infectious hepatitis C virus pseudo-particles containing functional E1-E2 envelope protein complexes. J. Exp. Med. 197, 633-642 CrossRef Medline

51. Hsu, M., Zhang, J., Flint, M., Logvinoff, C., Cheng-Mayer, C., Rice, C. M., and McKeating, J. A. (2003) Hepatitis C virus glycoproteins mediate $\mathrm{pH}-$ dependent cell entry of pseudotyped retroviral particles. Proc. Natl. Acad. Sci. U.S.A.100, 7271-7276 CrossRef Medline

52. Neculai, D., Schwake, M., Ravichandran, M., Zunke, F., Collins, R. F., Peters, J., Neculai, M., Plumb, J., Loppnau, P., Pizarro, J. C., Seitova, A., Trimble, W. S., Saftig, P., Grinstein, S., and Dhe-Paganon, S. (2013) Structure of LIMP-2 provides functional insights with implications for SR-BI and CD36. Nature 504, 172-176 CrossRef Medline

53. Acton, S., Rigotti, A., Landschulz, K. T., Xu, S., Hobbs, H. H., and Krieger, M. (1996) Identification of scavenger receptor SR-BI as a high density lipoprotein receptor. Science 271, 518-520 CrossRef Medline

54. Bartosch, B., Verney, G., Dreux, M., Donot, P., Morice, Y., Penin, F., Pawlotsky, J.-M., Lavillette, D., and Cosset, F.-L. (2005) An interplay between hypervariable region 1 of the hepatitis $C$ virus $\mathrm{E} 2$ glycoprotein, the scavenger receptor $\mathrm{BI}$, and high-density lipoprotein promotes both enhancement of infection and protection against neutralizing antibodies. J. Virol. 79, 8217-8229 CrossRef Medline

55. Hollingsworth, S. A., and Dror, R. O. (2018) Molecular dynamics simulation for all. Neuron 99, 1129-1143 CrossRef Medline

56. Zhang, Z., Gothe, F., Pennamen, P., James, J. R., McDonald, D., Mata, C. P., Modis, Y., Alazami, A. M., Acres, M., Haller, W., Bowen, C., Döffinger, R., Sinclair, J., Brothers, S., Zhang, Y., et al. (2019) Human interleukin-2 receptor $\beta$ mutations associated with defects in immunity and peripheral tolerance. J. Exp. Med. 216, 1311-1327 CrossRef Medline

57. Zhou, H.-X., and Pang, X. (2018) Electrostatic interactions in protein structure, folding, binding, and condensation. Chem. Rev. 118, 1691-1741 CrossRef Medline

58. Forni, D., Cagliani, R., Pontremoli, C., Pozzoli, U., Vertemara, J., De Gioia, L., Clerici, M., and Sironi, M. (2018) Evolutionary analysis provides insight into the origin and adaptation of HCV. Front. Microbiol. 9, 854 CrossRef Medline

59. Bertaux, C., and Dragic, T. (2006) Different domains of CD81 mediate distinct stages of hepatitis C virus pseudoparticle entry. J. Virol. 80, 49404948 CrossRef Medline

60. Grove, J., Nielsen, S., Zhong, J., Bassendine, M. F., Drummer, H. E., Balfe, P., and McKeating, J. A. (2008) Identification of a residue in hepatitis $\mathrm{C}$ virus E2 glycoprotein that determines scavenger receptor BI and CD81 receptor dependency and sensitivity to neutralizing antibodies. J. Virol. 82, 12020-12029 CrossRef Medline

61. Lindenbach, B. D., Meuleman, P., Ploss, A., Vanwolleghem, T., Syder, A. J., McKeating, J. A., Lanford, R. E., Feinstone, S. M., Major, M. E., LerouxRoels, G., and Rice, C. M. (2006) Cell culture-grown hepatitis C virus is infectious in vivo and can be recultured in vitro. Proc. Natl. Acad. Sci. U.S.A. 103, 3805-3809 CrossRef Medline

62. Lussignol, M., Kopp, M., Molloy, K., Vizcay-Barrena, G., Fleck, R. A., Dorner, M., Bell, K. L., Chait, B. T., Rice, C. M., and Catanese, M. T. (2016) Proteomics of $\mathrm{HCV}$ virions reveals an essential role for the nucleoporin Nup98 in virus morphogenesis. Proc. Natl. Acad. Sci. U.S.A. 113, 24842489 CrossRef Medline

63. Merz, A., Long, G., Hiet, M.-S., Brügger, B., Chlanda, P., Andre, P., Wieland, F., Krijnse-Locker, J., and Bartenschlager, R. (2011) Biochemical and morphological properties of hepatitis $\mathrm{C}$ virus particles and determination of their lipidome. J. Biol. Chem. 286, 3018-3032 CrossRef Medline 


\section{CD81 cholesterol sensing}

64. Wrensch, F., Crouchet, E., Ligat, G., Zeisel, M. B., Keck, Z.-Y., Foung, S. K. H., Schuster, C., and Baumert, T. F. (2018) Hepatitis C virus (HCV)apolipoprotein interactions and immune evasion and their impact on HCV vaccine design. Front. Immunol. 9, 1436 CrossRef Medline

65. Lohmann, V., Körner, F., Koch, J., Herian, U., Theilmann, L., and Bartenschlager, R. (1999) Replication of subgenomic hepatitis C virus RNAs in a hepatoma cell line. Science 285, 110-113 CrossRef Medline

66. Quast, T., Eppler, F., Semmling, V., Schild, C., Homsi, Y., Levy, S., Lang, T., Kurts, C., and Kolanus, W. (2011) CD81 is essential for the formation of membrane protrusions and regulates Rac1-activation in adhesion-dependent immune cell migration. Blood 118, 1818-1827 CrossRef Medline

67. Scarselli, E., Ansuini, H., Cerino, R., Roccasecca, R. M., Acali, S., Filocamo, G., Traboni, C., Nicosia, A., Cortese, R., and Vitelli, A. (2002) The human scavenger receptor class $\mathrm{B}$ type I is a novel candidate receptor for the hepatitis C virus. EMBO J. 21, 5017-5025 CrossRef Medline

68. Evans, M. J., von Hahn, T., Tscherne, D. M., Syder, A. J., Panis, M., Wölk, B., Hatziioannou, T., McKeating, J. A., Bieniasz, P. D., and Rice, C. M. (2007) Claudin-1 is a hepatitis $C$ virus co-receptor required for a late step in entry. Nature 446, 801-805 CrossRef Medline

69. Martin, D. N., and Uprichard, S. L. (2013) Identification of transferrin receptor 1 as a hepatitis $\mathrm{C}$ virus entry factor. Proc. Natl. Acad. Sci. U.S.A. 110, 10777-10782 CrossRef Medline

70. Lupberger, J., Zeisel, M. B., Xiao, F., Thumann, C., Fofana, I., Zona, L., Davis, C., Mee, C. J., Turek, M., Gorke, S., Royer, C., Fischer, B., Zahid, M. N., Lavillette, D., Fresquet, J., et al. (2011) EGFR and EphA2 are host factors for hepatitis $\mathrm{C}$ virus entry and possible targets for antiviral therapy. Nat. Med. 17, 589-595 CrossRef Medline

71. Susa, K. J., Seegar, T. C., Blacklow, S. C., and Kruse, A. C. (2020) A dynamic interaction between CD19 and the tetraspanin CD81 controls B cell co-receptor trafficking. eLife 9, e52337 Medline

72. Felmlee, D., Hafirassou, M., Lefevre, M., Baumert, T., and Schuster, C. (2013) Hepatitis C virus, cholesterol and lipoproteins: impact for the viral life cycle and pathogenesis of liver disease. Viruses 5, 1292-1324. CrossRef Medline

73. Homsi, Y., Schloetel, J.-G., Scheffer, K. D., Schmidt, T. H., Destainville, N., Florin, L., and Lang, T. (2014) The extracellular $\delta$-domain is essential for the formation of CD81 tetraspanin webs. Biophys. J. 107, 100-113 CrossRef Medline

74. Schmidt, T. H., Homsi, Y., and Lang, T. (2016) Oligomerization of the tetraspanin CD81 via the flexibility of its $\delta$-loop. Biophys. J. 110, 2463-2474 CrossRef Medline

75. Gillard, B. K., Randall Bassett, G., Gotto, A. M., Rosales, C., and Pownall, H. J. (2017) Scavenger receptor B1 (SR-B1) profoundly excludes high density lipoprotein (HDL) apolipoprotein AII as it nibbles HDL-cholesteryl ester. J. Biol. Chem. 292, 8864-8873 CrossRef Medline

76. Lupberger, J., Felmlee, D. J., and Baumert, T. F. (2012) Cholesterol uptake and hepatitis C virus entry. J. Hepatol. 57, 215-217 CrossRef Medline

77. van Meer, G., Voelker, D. R., and Feigenson, G. W. (2008) Membrane lipids: where they are and how they behave. Nat. Rev. Mol. Cell Biol. 9, 112124. CrossRef Medline

78. Rosenhouse-Dantsker, A., and Bukiya, A. N. (eds) (2019) Direct Mechanisms in Cholesterol Modulation of Protein Function, Springer, New York

79. Schuck, S., Honsho, M., Ekroos, K., Shevchenko, A., and Simons, K. (2003) Resistance of cell membranes to different detergents. Proc. Natl. Acad. Sci. U.S.A. 100, 5795-5800 CrossRef Medline

80. Bitzegeio, J., Bankwitz, D., Hueging, K., Haid, S., Brohm, C., Zeisel, M. B., Herrmann, E., Iken, M., Ott, M., Baumert, T. F., and Pietschmann, T.
(2010) Adaptation of hepatitis C virus to mouse CD81 permits infection of mouse cells in the absence of human entry factors. PLoS Pathog. 6, e1000978 CrossRef Medline

81. Culley, S., Towers, G. J., Selwood, D. L., Henriques, R., and Grove, J. (2016) Infection counter: automated quantification of in vitro virus replication by fluorescence microscopy. Viruses 8, 201 CrossRef Medline

82. Schneider, C. A., Rasband, W. S., and Eliceiri, K. W. (2012) NIH Image to ImageJ: 25 years of image analysis. Nat. Methods 9, 671-675 CrossRef Medline

83. Schindelin, J., Arganda-Carreras, I., Frise, E., Kaynig, V., Longair, M., Pietzsch, T., Preibisch, S., Rueden, C., Saalfeld, S., Schmid, B., Tinevez, J.Y., White, D. J., Hartenstein, V., Eliceiri, K., Tomancak, P., et al. (2012) Fiji: an open-source platform for biological-image analysis. Nat. Methods $\mathbf{9}$, 676-682 CrossRef Medline

84. Cox, J., and Mann, M. (2008) MaxQuant enables high peptide identification rates, individualized p.p.b.-range mass accuracies and proteome-wide protein quantification. Nature Biotechnol. 26, 1367-1372 CrossRef Medline

85. Orchard, S., Ammari, M., Aranda, B., Breuza, L., Briganti, L., BroackesCarter, F., Campbell, N. H., Chavali, G., Chen, C., del-Toro, N., Duesbury, M., Dumousseau, M., Galeota, E., Hinz, U., Iannuccelli, M., et al. (2014) The MIntAct project-IntAct as a common curation platform for 11 molecular interaction databases. Nucleic Acids Res. 42, D358-D363 CrossRef Medline

86. Perez-Riverol, Y., Csordas, A., Bai, J., Bernal-Llinares, M., Hewapathirana, S., Kundu, D. J., Inuganti, A., Griss, J., Mayer, G., Eisenacher, M., Pérez, E., Uszkoreit, J., Pfeuffer, J., Sachsenberg, T., Yilmaz, S., et al. (2019) The PRIDE database and related tools and resources in 2019: improving support for quantification data. Nucleic Acids Res. 47, D442-D450 CrossRef Medline

87. Chen, V. B., Arendall, W. B., 3rd, Headd, J. J., Keedy, D. A., Immormino, R. M., Kapral, G. J., Murray, L. W., Richardson, J. S., and Richardson, D. C. (2010) MolProbity: all-atom structure validation for macromolecular crystallography. Acta Crystallogr. D Biol. Crystallogr. 66, 12-21 CrossRef Medline

88. Jo, S., Kim, T., Iyer, V. G., and Im, W. (2008) CHARMM-GUI: a web-based graphical user interface for CHARMM. J. Comput. Chem. 29, 1859-1865 CrossRef Medline

89. Maier, J. A., Martinez, C., Kasavajhala, K., Wickstrom, L., Hauser, K. E., and Simmerling, C. (2015) ff14SB: improving the accuracy of protein side chain and backbone parameters from ff99SB. J. Chem. Theory Comput. 11, 3696-3713 CrossRef Medline

90. Salomon-Ferrer, R., Götz, A. W., Poole, D., Le Grand, S., and Walker, R. C. (2013) Routine microsecond molecular dynamics simulations with AMBER on GPUs: 2. Explicit solvent particle mesh Ewald. J. Chem. Theory Comput. 9, 3878-3888 CrossRef Medline

91. Le Grand, S., Götz, A. W., and Walker, R. C. (2013) SPFP: speed without compromise: a mixed precision model for GPU accelerated molecular dynamics simulations. Comput. Phys. Commun. 184, 374-380 CrossRef

92. Pettersen, E. F., Goddard, T. D., Huang, C. C., Couch, G. S., Greenblatt, D. M., Meng, E. C., and Ferrin, T. E. (2004) UCSF Chimera: a visualization system for exploratory research and analysis. J. Comput. Chem. 25, 16051612 CrossRef Medline

93. Tusher, V. G., Tibshirani, R., and Chu, G. (2001) Significance analysis of microarrays applied to the ionizing radiation response. PNAS 98, 51165121 CrossRef 